\title{
«AD USUM NOSTRORUM TANTUM» LA COMPAÑÍA DE JESÚS EN MI EPISTOLARIO CON EL PADRE REVUELTA
}

\author{
JAVIER BURRIEZA SÁNCHEZ ${ }^{1}$
}

RESUMEN: A la muerte del padre Manuel Revuelta, maestro de historiadores de la Compañía de Jesús, me percaté de que, además de un ejemplo profesional y científico de primer orden del cual había aprendido tanto, poseía un tesoro entre mis manos, una abundantísima correspondencia en la cual la Compañía de Jesús era una notable protagonista. A través de estas cartas aprendí a investigar a los jesuitas, a conocer a muchos de los autores de su historiografía, de los avances que se producían y recibí cada novedad, también desde el punto de vista personal, de la obra de nuestro protagonista, en la culminación de su carrera académica y científica. Por eso, he considerado oportuno abrir este epistolario y trazar desde él ese retrato intimo y, al mismo tiempo, profundamente universitario de Manuel Revuelta, desde 2003 en que fue miembro del tribunal de mi tesis doctoral, hasta 2019.

PaLABRAS Clave: Manuel Revuelta; Compañía de Jesús; jesuitas; historiografía de la Compañía; historiadores de la Compañía de Jesús; Universidad Pontificia de Comillas.

\section{"Ad Usum Nostrorum Tantum». The Society of Jesus in my epistolary with Father Revuelta}

ABSTRACT: Upon the death of Father Manuel Revuelta, Master of historians of the Society of Jesus, I realized that, in addition to a first-rate professional and scientific example from whom I had learned so much, I had a treasure in my hands, an abundant correspondence in which the Society of Jesus was a notable protagonist. Through these letters I learned to investigate the Jesuits, to meet many of the authors of their historiography, the advances that were taking place and I received each novelty, also from a personal point of view, of the work of our protagonist, in the culmination of his academic and scientific career. That is the reason why I have considered it was appropriated to open this epistolary and draw that intimate and, at the same time, deeply academic portrait of Manuel Revuelta, from 2003 when he was a member of the tribunal for my doctoral thesis, until 2019.

KEY WorDS: Manuel Revuelta; Society of Jesus; Jesuits; historiography of the Society of Jesus; historians of Society of Jesus; Comillas Pontifical University.

1 Profesor Titular Historia Moderna. Universidad de Valladolid. Correo electrónico: javierburrieza@movistar.es 
Unos días después de la muerte de Manuel Revuelta, pensé reunir la abundante correspondencia que habíamos mantenido a lo largo de los años, desde que nos conocimos en 2003. Me percaté de su carácter constante, por ambas partes, aunque mucho más rica la suya en indicaciones y apreciaciones. Correspondencia que, como indicaban los tiempos, casi nunca fue en papel aunque también dispongo de algunos autógrafos - sino muy especialmente, por el correo electrónico. Cartas, por tanto, que cobran ahora un gran valor y que necesitaban, por mucho que se empeñen los impulsores de las grandes tecnologías, de un soporte mucho menos efímero. Podíamos perder la continuidad de la misma en medio de un cambio informático. Comencé, pues, a ordenarla y a constituir el puzzle. Junto a apreciaciones personales, esa correspondencia que, para mí era un tomo de mi particular Monumenta Historica Societatis Iesu, contenía numerosos aspectos interesantes para abordar la historia y la historiografía de la Compañía de Jesús, en este tiempo en que abundantes han sido los estudios procedentes desde distintas Universidades.

\section{APRENDIZ DESDE UNA TESIS DOCTORAL SOBRE LA COMPAÑÍA DE JESÚS}

Todo comenzó cuando estaba concluyendo mi tesis doctoral: «El poder de la enseñanza y el sermón: presencia de la Compañía de Jesús en el ámbito geográfico de Valladolid (1545-1767)», dirigida por mi maestro Teófanes Egido, gran amigo de Manuel Revuelta desde hacía muchos años. Era el momento de pensar en la propuesta que había que elevar a la Comisión de Doctorado de la Universidad de Valladolid para constituir el tribunal que debía evaluar la mencionada Tesis Doctoral. Era menester designar desde el Departamento de Historia Moderna, Contemporánea y América - que entonces éste era su nombre- diez doctores para que aquella Comisión designase cinco. La propuesta debía subrayar la presencia de un historiador jesuita que, con independencia a su especialidad temporal, pudiese tener una visión global de la Compañía de Jesús. Sin duda, ése debía ser Manuel Revuelta. Yo le había escuchado y visto, hasta entonces, en una sola ocasión, en el III Congreso de Historia de Palencia (Revuelta, 1995, pp. 323-386); le había leído y, sobre todo, había empezado a aprender mucho de sus obras. No me atrevía a dirigirme a él, pues pensaba que lo tenía que hacer la Comisión de Doctorado, la competente en estas materias después de que nosotros supiéramos que ya había sido asignado para formar parte del tribunal. Sin embargo, a Cantoblanco, a la Residencia de Profesores de Comillas, le llegó el aviso 
académico al mismo tiempo que los dos tomos que constituían la tesis. Allí ejercía su docencia en Historia en aquella Universidad.

Con todo, me arriesgué aquel 27 de febrero de 2003, con la carta que inicia este singular epistolario ${ }^{2}$. En lo que iba a ser una costumbre en él, respondió al día siguiente. "Yo suelo ser reacio a intervenir en tribunales de tesis, pero en este caso participaré con gusto y aprenderé mucho». Aquello había sido un "hecho consumado»: "Le felicito muy sinceramente por el magnífico trabajo realizado en su tesis. Sólo he tenido tiempo para leer el índice y hojearla rápidamente; pero es suficiente para recibir una magnífica impresión por la amplitud y profundidad con que ha tratado un tema tan importante en el campo educativo, religioso y cultural en general». Yo no le había dicho nada acerca del próximo nacimiento de mi primera hija, pero él ya lo había leído en la dedicatoria de mi tesis. Aquel sabio, en su cotidianidad, unía conocimiento, amabilidad y afecto desde el primer momento en que le conocías: «estoy seguro de que la brillante culminación de su doctorado se añadirá a la ilusión con que usted y María José esperan a la hija que aumentará la alegría de su hogar». Su sentido familiar siempre sería una constante en sus cartas (Revuelta, 28.II.2003).

Muy pronto, incluso antes de la lectura de aquella tesis, este historiador consideró que debía incluirme en distintos proyectos historiográficos de la Compañía. Me puso en contacto con el jesuita José del Rey, en su estudio de la Universidad Pontificia Javeriana de Bogotá, donde estaba coordinando un estudio sobre su biblioteca — «estaba leyendo su tesis y me tomé la libertad de darle su nombre, pues estaba seguro de que el intercambio científico les ayudará a los dos» (Revuelta, 2.IV.2003)—. En ese mismo momento ya me hacía partícipe de un artículo suyo sobre la expulsión de los jesuitas de 1767, «a propósito del libro de los de Alicante». Se estaba refiriendo al equipo de

2 «Apreciado doctor Revuelta. Como le habrá confirmado la Universidad de Valladolid, la Comisión de Doctorado ha tenido a bien tener en cuenta la recomendación que hicimos tanto mi director el profesor Egido López como yo mismo, para que usted formase parte de mi Tribunal de Tesis Doctoral sobre los jesuitas en Valladolid. Le agradecería que me informase de la llegada de la Tesis Doctoral, pues se la envié ayer tarde por postal express y estas cosas siempre despiertan un tanto de atención en el doctorando (empresa en la que uno casi siempre es primerizo). Tanto el profesor Luis Ribot (como presidente del tribunal) como Alberto Marcos (como secretario), así como Teófanes Egido se pondrán en contacto con usted para fijar la fecha de la lectura de la Tesis. Por otra parte, en el plazo de un mes debe enviar a la Comisión de Doctorado un informe siguiendo el formulario que le he remitido y a la dirección que le he podido facilitar», en Carta de Javier Burrieza a Manuel Revuelta, Valladolid 27.II.2003. A partir de ahora citaremos con el apellido de quien escribe la carta y la fecha de la misma. 
investigación que existía en aquella Universidad, encabezado por Enrique Giménez y dedicado, no solo al estudio de la expulsión del 2 de abril de 1767 sino a todas las consecuencias políticas del extrañamiento y disolución de la Compañía. "Mañana (o tal vez hoy, pues está a punto de cambiar el día) se celebrará en la Universidad de Comillas un acto en homenaje al P. José María Rubio, al que canonizará el Papa [Juan Pablo II] cuando venga a Madrid. Hablaremos cinco profesores. Como es usted especialista en historia jesuítica le envío las palabras que yo diré. A ver si le gustan» (Revuelta, 2.IV.2003). Pocos días después, José del Rey me escribía y me encomendaba el análisis de la sección de la biblioteca conformada por los autores «concionatores», los predicadores y sus sermones: «tengo mucha fe en este proyecto que pienso puede ser innovador y dar luces, al menos aquí en América, para acceder a un futuro estudio de las mentalidades» (José del Rey, 9.V.2003) ${ }^{3}$.

La lectura de la Tesis se produjo el 5 de mayo de 2003, el lunes siguiente a la canonización por el papa Wojtyla del jesuita san José María Rubio, en compañía de otros cuatro religiosos, en la Plaza Colón. En ese mismo momento, tras haber concluido todo, Revuelta, Teófanes Egido y yo, firmábamos el contrato con la editorial Marcial Pons y con la Fundación Carolina para la publicación de un libro que se habría de titular Los jesuitas en España y en el Mundo Hispánico: «todavía no he comenzado» —escribía Revuelta unas semanas más tarde- «la parte que me encargó Teófanes en la historia tripartita jesuítica en la que tú colaboras como gran especialista. Espero poder hacer algo para el verano»(Revuelta, 15.VI.2003). Tras su conclusión y publicación, el historiador siempre tuvo buena información de cómo estaba siendo recibido el libro por el público lector y especializado, a través de esas recensiones que él, en su realización, dominaba. Estaba constantemente atento a las que iban apareciendo en distintos medios. Se mostraba muy cortés, procuraba que pudiésemos responder uno de los tres autores a cada uno de los responsables de esas recensiones, que se iban

3 Finalmente, en la obra editada por José del Rey Fajardo y Myriam Marín Cortés, me encargué de la sección de los Concionatores (predicadores y sus sermones, pp. 347-394) y Vidas de los santos y de las santas (pp. 657-726), cfr. La Biblioteca Colonial de la Universidad Javeriana comentada, Bogotá, Pontificia Universidad Javeriana, 2008. José del Rey, profesor titular de la Universidad Católica Andrés Bello de Caracas, doctor en Letras por la Universidad de Los Andes en Mérida y en Historia por la Pontificia Universidad Javeriana, académico de número de la Academia Nacional de la Historia de Venezuela, rector fundador de la Universidad Católica del Táchira, también en Venezuela; doctor honoris causa por distintas universidades; autor de una ingente producción histórica dedicada sobre todo al estudio de las mentalidades en el Nuevo Reino de Granada, a las formas culturales de las misiones jesuíticas en la Orinoquia y de la pedagogía colonial de la Compañía de Jesús. 
multiplicando cada vez más ${ }^{4}$. Me llamaba la atención cómo Revuelta conocía a cada uno de los que se habían interesado por la obra, casi como si tuviese una ficha de cada uno de ellos: «Antoni Borrás, ya está jubilado, es profesor emérito, fue gran bibliotecario de Sant Cugat, hombre muy culto e historiador minucioso. Actualmente, es director del Arxiu del Palau Requesens y vocal de la Comissió Coordinadora Generalitat-Església del Patrimoni Cultural» (Revuelta, 12.IX.2005). Me recordaba aquella forma de escribir e informar de los primeros «compañeros» y padres acerca de las personas que conocían en el proceso fundacional de la Compañía ${ }^{5}$.

En una de esas cartas, me confesó que «nuestro libro tripartito», como alguna vez lo denominó, había sido seleccionado para ser presentado para el Premio Nacional de Historia: «parece que lo introdujo Carmen Labrador, que formaba parte del jurado y que lo eliminaron enseguida. Al cabo se lo dieron a Santos Juliá, como sabes. De todos modos, el hecho de entrar en el campeonato ya es mérito y debe alegrarnos como el equipo español que al fin va a jugar el mundial» (Revuelta, 20.XI.2005). Ese mismo día, horas más tarde, me confirmaba cómo había sido la propuesta que había realizado la gran especialista en la Ratio Studiorum:

4 «Los tres autores coinciden también en cualidades comunes» —escribía su amigo y compañero Rafael Sanz de Diego-. «Los tres escriben con estilo ágil que hace fácil la lectura, incluso cuando tratan temas hondos, que precisan matices [...] Los tres han coincidido en oír a los jesuitas y a sus adversarios, a la oficialidad jesuítica y los discrepantes dentro de la Orden. Burrieza recoge ecos de Melchor Cano, Siliceo y los memorialistas. Egido oye a Campomanes y lee los diarios de los jesuitas expulsos. Revuelta se hace cargo de la novela antijesuítica y espiga memorias inéditas de jesuitas contemporáneos, que se ocupó de recopilar. Todo esto hace del libro una obra muy valiosa, sin precedente en España que hace asequible una historia que merece ser conocida objetivamente», en Sanz de Diego (2005).

5 «Me dijo [el padre José del Rey] también que "nuestro" libro está gustando mucho por aquellas tierras [de Venezuela]; que el instructor de Tercera Probación de Venezuela se lo hace leer a sus tercerones y que lo mismo hacen en Miami con los cubanos», en Revuelta, 28.I.2006; «En el mismo número [hablaba de Archivo Teológico Granadino] he visto una recensión que no conocía, de "nuestro" libro de la que tampoco tenía noticia. Es breve (se reduce a enjuiciar los capítulos) pero elogiosa y, especialmente valiosa porque el autor, el P. Estanislao Olivares, es hombre crítico (fue, con Castillo uno de los alejados de la docencia en la Facultad de Teología de Granada, por lo que Olivares es ahora profesor en la Facultad de Filosofía de la Universidad Civil). El recensor reconoce la dificultad de escribir un libro sobre el tema, pero lo alaba en su conjunto y en la parte de cada uno de los autores. Dice que «lo han conseguido los autores de este excelente manual». Señala el "gran poder de síntesis» de Javier Burrieza, la «sobriedad y serenidad» en el capítulo de Egido dedicado a la expulsión y la "exactitud" de Revuelta en "la más difícil todavía" última parte», en Revuelta, 9.II.2006. 
Carmen Labrador es profesora (creo que catedrática) de Historia de la Educación en la Complutense. Hace unos años fue profesora en Comillas, donde actuó como tutora de la Infanta Elena, cuando estudió aquí Pedagogía. Siempre ha colaborado mucho con Comillas y con los jesuitas. Yo me enteré de su propuesta no por ella, sino por un amigo. La verdad es que merece nuestra gratitud, y voy a escribirla en nombre de los tres. (Revuelta, 20.XI.2005)

Efectivamente, Carmen Labrador no se lo contó a Revuelta sino, únicamente, al entonces vicerrector de Comillas Juan Manuel Cobo. El afecto entre ambos profesores, Labrador y Revuelta era mutuo y de una profunda admiración. Se trataba de la profesora que conocí y subrayé intensamente mientras realizaba mi tesis doctoral y estudiaba su edición de la Ratio Studiorum. Después ella aceptó la invitación, con motivo del III centenario de la muerte de san Juan Bautista De La Salle, de realizar un magnífico capítulo acerca de la relación entre los lasalianos y los jesuitas a través de esta obra cumbre de la educación que tanto había estudiado. Libro que ella misma presentó en Madrid (Labrador, 2019).

"Me complace también verte tan identificado con nuestras cosas y "modo de proceder"». Esta observación me la habría de realizar Revuelta en multitud de ocasiones. Le preocupaba mucho la ausencia de vocaciones de historiadores jesuitas, a pesar de la buena prensa que la Compañía poseía: «así como en los colegios el peso lo llevan ahora los profesores seglares, algo parecido está pasando en la investigación histórica, que está siendo cultivada por historiadores no jesuitas, atraídos por el aliciente que encierra en sí la historia de la orden» (Revuelta, 29.I.2006). En aquellos momentos, teniendo pendiente la publicación de la tesis o de parte de ella, iniciaba un libro sobre la presencia de los jesuitas en América, encargado por el proyecto de investigación de la recién nacida Cátedra de Estudios Hispánicos del Instituto Universitario de Historia «Simancas» de la Universidad de Valladolid. Una iniciativa financiada por el empresario leonés Antonino Fernández, dueño de cervezas «Coronitas». La obra se habría de titular Jesuitas en Indias, entre la utopía y el conflicto $(2007)^{6}$. Uno de los temas que deseaba desarrollar en

6 «Recibí tu carta horas antes de ir a Salamanca a tener una conferencia sobre las Reducciones del Paraguay en los dominicos. Salió muy bien. Cuando la tenga pulida (pues la tengo que dar también en Bilbao y San Sebastián con algunos retoques), te la mandaré; no para que aprendas lo que sabes mejor que yo sino para que te estimule en el buen libro que estás preparando sobre los jesuitas en América»", en Revuelta, 9.II.2006; «En San Sebastián tuve una nueva versión de mi conferencia sobre las Reducciones, esta vez bajo la perspectiva de la inculturación. En Bilbao fue sobre la utopía y realidad. En Salamanca sobre gloria y tragedia. Las reducciones tiran y enganchan, a lo que ayuda la película "La Misión". Un éxito de público, correcto e interesado en los tres sitios», Revuelta, 9.III.2006. 
el libro era la relación entre evangelización y música, especialmente en las reducciones de frontera. Para eso me puso en contacto con el jesuita Enrique Climent, que había trabajado intensamente en la «ópera de San Francisco Javier» compuesta por un indígena chiquitano —en la actual Bolivia- a comienzos del siglo XVIII, sin olvidar las aportaciones del padre Domenico Zipoli.

Fue muy importante la invitación que, a principios de 2006, recibí para asistir como ponente a las III Jornadas que organizaba la Facultad de Teología de Comillas en el siguiente octubre. Me llegó por Santiago Madrigal, su decano ${ }^{7}$, y con la buena recomendación de Revuelta. El hilo directriz era los aniversarios ignacianos en torno a Ignacio de Loyola, Francisco Javier y Pedro Fabro. Me pedían que realizase, a través de una ponencia marco, «un retrato histórico de los orígenes» de la Compañía ${ }^{8}$, que después pudiese ser publicado en la mencionada revista Estudios Eclesiásticos. Fueron días muy importantes en mi percepción de la orden. Por vez primera iba a vivir entre jesuitas, en lo que se llamaba la Casa de Escritores -así conocida porque moraban los que escribían en las revistas de la orden- de la calle madrileña de Pablo Aranda, en una comunidad formada por el propio rector de Comillas, José Ramón Busto; el académico Quintín Aldea9 ${ }^{9}$ el filósofo José Gómez Caffarena ${ }^{10}$, el escritor Pedro Miguel Lamet — para mí esencial, porque le-

7 «Me parece estupendo que los ponentes elegidos seáis gente joven, especialmente tú. Creo que te ofrecen la primera de las ponencias, y estoy seguro de que lo harás divinamente. Participará también otro joven historiador no SJ, Francisco Javier Gómez Díaz, que hizo su tesis sobre los jesuitas de Centroamérica, en el siglo XX, pero ha escrito también sobre las antiguas misiones. Hace poco coordinó el $\mathrm{n}^{\circ} 7$ de Cuadernos Americanos Francisco Vitoria, que recoge una serie de cuatro conferencias sobre La Compañía de Jesús en la América Española (siglos XVI-XVIII)» (Revuelta, 9.II.2006).

8 «En el congreso encontrarás a gente que te podrá informar de los temas que deseas con mucho más conocimiento que yo, por ejemplo, el P. José García de Castro o el P. Arzubialde, que son expertos en espiritualidad ignaciana. Tiene interés en hablar contigo el P. Jesús Sanjosé (director de Razón y Fe) sobre cosas de la historia de Valladolid. Procuraré que nos acompañe a comer cuando pases por Cantoblanco y también el P. Manuel Gallego (anterior rector de Comillas). Los dos residentes de esta casa, vallisoletanos de pro y antiguos alumnos de San José» (Revuelta, 14.X.2006).

9 «Me acaba de comunicar el P. Lamamié, de Salamanca, que hoy al mediodía ha fallecido el padre Quintín Aldea. Seguramente ya estaréis enterados del óbito, pero os lo comunico por si acaso. Recemos porque Dios le reciba con su abrazo de amor y demos gracias por su trabajo científico, intelectual y espiritual» (Burrieza, 31.I.2012). Cfr. Revuelta, 2018.

10 "Sereno siempre, sonriente y de una profunda elegancia espiritual —respondiendo a su retrato, Pedro Miguel Lamet-, su trayectoria entronca de forma brillante y eficaz con grandes compañeros suyos que contribuyeron a la puesta al día de la 
yendo su biografía sobre Pedro Arrupe comenzó mi vocación historiográfica por la Compañía- , el propio decano de Teología Santiago Madrigal o el sacerdote muy próximo, en tiempos, al cardenal Tarancón, José María Martín Patino ${ }^{11}$. Hoy, la antigua Casa de Escritores, junto al Archivo Histórico Nacional, aquel chalé del Madrid en expansión de principios del siglo XX, ya no es propiedad de la Compañía de Jesús. No fue la única ocasión de mi residencia allí. Incluso, en sus salones, nos reunimos por vez primera el grupo de investigación que pude dirigir desde 2012 sobre espiritualidad femenina. Para mí se convirtió en un lugar referencial. La última vez que estuve delante de sus muros, una empresa constructora lo estaba reformando. Una experiencia vital que, de alguna manera se repitió años después, en el Congreso Internacional Los jesuitas: religión, politica y educación (siglos XVI-XVIII), que se celebró en Madrid en junio de $2011^{12}$. Un congreso multitudinario que después fue convenientemente publicado y en cuya organización Revuelta se sentía implicado. Quizás fue allí el último encuentro con el historiador del arte Fernando Gutiérrez, otro de los hombres del Japón. Y todavía volvió a suceder mientras fui profesor del Máster Ignaciano de la Facultad de Teología de la Universidad de Comillas y me hospedaba en la comunidad de la Residencia de Profesores como después describiré.

Esa relación de magisterio y amistad tuvo también gestos de mucho cariño. En sus habituales cartas plasmaba lo que sintió cuando recibió mi libro La Compañía del padre Hoyos (2010) dedicado a su persona y publicado en torno a la beatificación de este jesuita vallisoletano del siglo XVIII en la Acera

Iglesia antes y después del Concilio Vaticano II, los padres José María de Llanos y José María Díez-Alegría. Pero si estos lucharon para dar credibilidad a la fe cristiana en ambas Españas desde la praxis del suburbio y la renovación de la teología. Caffarena lo llevó a cabo a partir de un pensamiento filosófico hermenéutico y dialogante [...] Pulcro, ordenado y metódico en sus horarios hasta la saciedad, era sobre todo un gran compañero de todos y un amigo [...] Los últimos cinco años he concelebrado con él la eucaristía diariamente. Era su momento cumbre del día. En su extraordinaria cabeza, que conservó hasta el final, confluían la exégesis bíblica, la devoción y el sentido común, abierto al mundo y las gentes de hoy», en Lamet, P.M., Ha fallecido José Gómez Caffarena SJ, miércoles 6 febrero 2013.

11 «Aquí quedaron todos muy bien impresionados con tu conferencia y con tu trato. Quedaste como el Niño Jesús entre los doctores. Supongo que tu quedarías también satisfecho de tu estancia entre nosotros» (Revuelta, 26.X.2006).

12 «Mucho me alegra que aceptes la invitación a participar en el congreso. Me parece muy interesante el tema que propones, que de momento vale como título provisional: La fundación de los colegios y el mundo femenino", en Revuelta, 19.II.2010. Cfr. Martínez Millán, J., Pizarro, H., Jiménez, E. (coords.) (2012). Martínez Millán era discípulo de Revuelta. 
de Recoletos de la ciudad ${ }^{13}$, un 18 de abril de 2010. No ha sido el único libro a él dedicado, pues meses después de su muerte hice lo propio con la nueva edición ampliada de la Guía misteriosa de Valladolid. Pero el del padre Hoyos, publicado por Sal Terrae y en vísperas de la beatificación, era propio de la historia de la Compañía. Con su manejo de la narrativa epistolar me describió cómo se extrañó cuando leyó mi carta introductoria:

[...] me pareció raro lo de "te dedico este libro por escrito y por manuscrito». Entonces reparo en lo que está escrito en letras de imprenta en la misma página, y veo en letras de molde mi nombre y apellido en la dedicatoria. La sorpresa se hizo mayúscula y gratísima. Quedé, como decía Alfonso Guerra, "pasmao». Me complace todavía más el verme acompañado por Isidoro Pinedo, buen amigo desde que colaboramos en Deusto. No sé, cómo agradecerte esta doble dedicatoria, en un libro dedicado a la Compañía y al P. Hoyos, que tiene como telón de fondo a Valladolid, una ciudad para mí tan querida. Creo que es un acierto haber escrito esta biografía ambiental para encajar la figura del P. Hoyos ${ }^{14}$.

13 «La reciente beatificación del P. Hoyos ha dado lugar a no pocas celebraciones orales y escritas, unas de carácter popular, otras de noveles más especializados. Una confluencia armoniosa de estas dos tendencias aparece en esta biografía, escrita por un gran especialista con una agilidad de estilo que encantará a todos los públicos. Es una biografía bien documentada, como era de esperar en Javier Burrieza [...] La mayor originalidad del autor, y a nuestro juicio su mayor mérito, consiste en habernos ofrecido un ejemplo de biografía ambiental [...] El encuadre de la persona en su ambiente es siempre un acierto, pero en este caso está más justificado, al tratarse de la vida de un hombre joven, sin llamativas aventuras exteriores. Los autores barrocos solían llenar estos vacíos con panoramas celestiales. El autor de La Compañía del P. Hoyos encuentra la solución acertada al situarlo en los panoramas culturales y religiosos que rodearon su existencia y nos ayudan a comprender su vida escondida, su espiritualidad y su influencia», en Recensión de Manuel Revuelta de La Compañía del Padre Hoyos.

14 Revuelta, 4.V.2010. La dedicatoria decía: «A Manuel Revuelta González e Isidoro Pinedo Iparraguirre, de la Compañía de Jesús, amigos que siempre me han guiado en mis investigaciones, con mi amistad y admiración». "Era la gran sorpresa -le respondía yo- que quería daros a los dos. Confiaba que ningún jesuita se me adelantara y os lo dijera. Isidoro [Pinedo] estuvo aquí el otro día y pude dárselo. A ti te lo he enviado. Es un signo de agradecimiento de lo mucho que has hecho por mí siempre, leyendo con paciencia mis escritos, valorándolos con benevolencia y misericordia (mañana hace siete años de la lectura de mi tesis doctoral), de la palabra de recomendación hacia los demás de mis trabajos y de mi persona. Todo eso debe ser agradecido en alguna ocasión y esta podía ser una ocasión bonita. Por eso, entiende que el profundo agradecimiento y satisfacción por ser amigo tuyo es el mío. No veas como he disfrutado yo pensando cómo podía darte la sorpresa», en Burrieza, 4.V.2010. 
Isidoro Pinedo fue otro de los grandes amigos jesuitas desde mis comienzos investigadores en la Compañía, aunque lo conocí en persona más tarde. En realidad, lo había leído en aquel libro de Las causas gravísimas y secretas de la expulsión de los jesuitas por Carlos III que había escrito junto a Teófanes Egido. Su conocimiento vino desde el grupo de investigación de la Universidad de Alicante, con el que se encontraba muy unido, con los mencionados Enrique Giménez e Inmaculada Fernández Arrillaga ${ }^{15}$. Pensemos que Pinedo es el que tuvo que dar el «consentimiento» a esta profesora para manejar el amplísimo e inabarcable diario del padre Luengo, documento que no pudo consultar Miquel Batllori, considerando éste que los "castellanos» no se lo habían dejado examinar. Después mi relación con Pinedo, hasta su muerte en Loyola en enero de 2018, fue muy personal y cercana, familiar y enriquecedora. Gustaba mucho de venir a Valladolid, esta ciudad del Pisuerga que querían tanto Revuelta como este jesuita de Deusto, especialista en el siglo XVIII.

Antonio Astorgano (Astorgano, 2020) puso en relación también el retrato como historiador de Manuel Revuelta — profesor, investigador y divulgador - con otros jesuitas como el mencionado Miquel Batllori, el académico Quintín Aldea o Gonzalo Díez, este último desde el ámbito de la historia del Derecho, pero también con la célebre monografía sobre El Cid. Batllori, que murió en 2002, estaba llamado a tener un importante papel en el libro tripartito que me unió con los grandes maestros Egido y Revuelta. Así fue definido por este último:

[...] fue el verdadero impulsor de las investigaciones sobre los jesuitas exiliados en el siglo XVIII. Es un historiador de todas las épocas de la cultura española y, en consecuencia, de todos los siglos de la Compañía. Su producción historiográfica es impresionante. Sus trabajos revelan erudición, claridad, solidez

15 Giménez López, E. (ed.) (2010). Aspectos de la política religiosa en el siglo XVIII. Estudios en Homenaje a Isidoro Pinedo Iparraguirre SJ. Allí podemos leer un interesante prólogo del que también fue jesuita y condiscípulo de Pinedo, Gaizka de Usabel, otro de mis nombres imprescindibles en el descubrimiento de la humanidad de la Compañía: «Isidoro Pinedo es parte de una generación de historiadores jesuitas que estudiaron en Zaragoza y se especializaron en temas del siglo XVIII. Rafael Olaechea le animó y le aconsejó escribir su tesis doctoral sobre Manuel de Roda, el primer ministro escogido por Carlos III. José Antonio Ferrer Benimeli colaboró en investigaciones de historia y en proyectos de la Compañía [será el autor del libro sobre la Expulsión publicado por el grupo editorial de la Compañía]. A esta generación pertenecen también otros historiadores y amigos suyos. Entre ellos, los jesuitas Manuel Revuelta y José del Rey Fajardo [...], junto con el carmelita descalzo Teófanes Egido. Esta generación ha formado e inspirado hornadas de historiadores que hoy publican y enseñan en las universidades...» en Usabel (2010), p. 12. 
y finura de interpretación. Era hombre de conversación chispeante y espíritu abierto, dispuesto siempre a ayudar a los historiadores primerizos. (Revuelta, 2017, p. 313)

\section{MANUEL REVUELTA Y VALLADOLID}

Mucho significaba la antigua Corte de los Austrias para la vida de este jesuita historiador. Desde su pueblo natal, Población de Campos, vino a estudiar al colegio de San José, fundado en 1881, cuando esta ciudad de los años cuarenta —él había nacido el $1^{\circ}$ de enero de 1936 - era «un tanto destartalada». Un bachillerato que se extendió entre 1946 y 1953, siguiendo el plan del ministro de Educación Nacional, Pedro Sainz Rodríguez, con la Ley de septiembre de 1938. Este centro de jesuitas respondía en su fundación a las grandes casas educativas de la Restauración canovista, según expresó Revuelta en el prólogo del estudio ofrecido por Luis Fernández en $1981^{16}$. De alguna manera era rival del establecido por Paulina Harriet en 1884 con los Hermanos de La Salle, bajo la advocación de Nuestra Señora de Lourdes. Curiosamente el que habría de ser cardenal Ángel Herrera Oria estudió las primeras letras en este último y el bachillerato con los jesuitas. Una rivalidad que contempló Revuelta en sus días de estudiante y que me puso de manifiesto cuando recibió mi monografía sobre el colegio lasaliano en 2009, al cumplirse los ciento veinticinco años de su fundación:

Yo tengo mucho cariño a los buenos hermanos de la Salle, hombres sacrificados y humildes con una gran vocación de maestros cristianos. Mucho me ha

16 Luis Fernández Martín (1908-2003) fue un singular historiador jesuita que abrió muchos caminos y, siempre con generosidad, propició que otros los transitasen, aunque su obra fue muy abundante, precursor por tanto de lo que, desde Valladolid, se ha aportado en los últimos años a la historiografía sobre la Compañía. Manuel Revuelta escribió sobre él una de sus pocas biografías en el Diccionario Biográfico Español de la Real Academia de la Historia. Palentino de Villarramiel de Campos, vivió la disolución de 1932, profesor en colegios, locutor de Radio Vaticana y, sobre todo, hombre de educación en los ámbitos de la FERE. Académico correspondiente de la Historia, en el último periodo de su vida intensificó sus labores como investigador. Fue toda una autoridad en la trayectoria de ciertos colegios de la Compañía, pero sobre todo en los años juveniles de Ignacio de Loyola. Tres meses antes de su muerte le pudimos rendir un homenaje las Universidades de Valladolid y León, dentro de un congreso sobre el padre Isla, del cual publicó su correspondencia inédita y editó su obra más importante, la Historia de fray Gerundio de Campazas alias Zotes. Cfr. Revuelta, M., «Fernández Martín, Luis» en Diccionario Biográfico Español, Madrid, Real Academia de la Historia, t. XIX, pp. 258-259. 
gustado [se refería a las fotografías del libro del Colegio de Lourdes, Lourdes, stella in Castella] ver al Hermano León [director que fue del centro], hombre muy simpático. Nos invitó un día a comer en el colegio a mi padre y a mí, cuando pasó por el centro un gran superior de la Salle, que fue fundador en América, que era de mi pueblo y amigo de mi padre. Entonces había una sana emulación entre Lourdes y San José, especialmente en deportes, cuando jugaban a baloncesto o al fútbol. Recuerdo una final de fútbol de los dos colegios en el estadio Zorrilla. Ganaba Lourdes 1-0, y como los de San José no eran capaces de ganar, el Rector de San José, que era el P. Valentín García, muy autoritario dio un pitido como si fuera el árbitro, y mandó retirar al equipo de San José, sin terminar el partido, ante el estupor de todo el mundo. Soberbia jesuítica tal vez. Luego en una revista o publicación de Lourdes salió un comic del partido, con el jesuita dando el pitido. Debió ser por el año 47 ó 48. Los «baberos» tenían fama de enseñar en la práctica mejor que los jesuitas, y había chicos que no aprobaban en San José y los Hermanos les hacían aprender. Los dos colegios han sido los grandes educadores de Valladolid y su comarca. Nadie quitará a Lourdes la gloria de Delibes. (Revuelta, 9.XII.2010)

Era, ésta del Pisuerga, la ciudad de su vocación —entró en la Compañía a principios de octubre de 1953-, de su ordenación sacerdotal en su Catedral el 14 de julio de 1966 por el conocido obispo jesuita monseñor Federico Melendro - arzobispo de Anking, en China ${ }^{17}$ - y también del lugar donde murió su padre. La última vez que viajó a ella, tras otras conferencias que pudimos compartir, fue en abril de 2018 cuando vino a tomar posesión de su condición de perito histórico del proceso de la monja dominica y fundadora Teresa Ortega, ante el cardenal Blázquez. Fue el único asunto del que me costó convencerlo después de la experiencia que había tenido en otros procesos como éstos y cumpliendo aquel papel. Así pues, la vocación como historiador jesuita se encontraba dentro de otra mayor que era, naturalmente, la pertenencia a la Compañía de Jesús desde 1953. Revuelta subrayaba que el gran momento fue la decisión de convertirse en jesuita, «todo lo que yo haya podido hacer después son simples etapas de la ruta que tomé en ese momento inicial. Las clases que he dado, los sermones que he predicado, las páginas que he escrito son acciones secundarias al lado de aquella decisión». Así lo confesaba en la homilía de la Eucaristía donde celebraba las bodas de oro de su entrada en el Instituto ignaciano. Confesaba que:

17 Aunque no estuvo presente en la correspondencia, sí en la conversación de nuestros encuentros: Manuel Revuelta demostró gran aprecio y veneración hacia el ejemplo de monseñor Melendro, palentino de la comarca de Valdavia desde 1889, afectado por la China comunista. Después repartió su existencia entre la Universidad Pontificia de Comillas y la Residencia de Palencia, aunque murió en Villagarcía de Campos en octubre de 1978. 
[...] había un ambiente de alta espiritualidad en el colegio San José de Valladolid, donde la religión entraba por todos los poros; una Compañía de Jesús pletórica; unos jesuitas atrayentes que sabían por dónde se andaban; un clima de piedad lleno de arrebatos sentimentales. Tiempos de posguerra austera y exaltada en la que surgían vocaciones a borbotones. Todos estos condicionamientos históricos influyeron indudablemente en mi decisión. Pero no los veo como elementos ofuscadores de la verdad, sino como instrumentos de la Providencia con los que el Señor reforzó la llamada que me hizo. Él golpeó entonces los oídos de mi alma y me dio la fuerza suficiente para decir que sí. Hice lo que tenía que hacer. De ello me felicito. En ello encuentro seguridad. (Cincuenta años de Compañía de Manuel Revuelta, Carta 26.X.2006)

Este palentino era hijo único de unos padres que, asumiendo aquella decisión, actuaron con un «cristianismo recio y coherente», respetando también su libertad: "cuando me dejó mi padre ${ }^{18}$ en el noviciado de Salamanca me dijo: "Manolo, mira qué puertas tan grandes para que te escapes" ». Pero él también quería resaltar la generosidad que demostraron. Aquel colegio de San José siempre estuvo en su horizonte vital. Por eso, no resulta extraño que en junio de 2014, su Asociación de Antiguos Alumnos le nombrase «Antiguo Alumno Distinguido».

\section{EL IMPORTANTE PAPEL DEL JESUITA HISTORIADOR}

Quizás podemos hablar de Manuel Revuelta como de uno de los últimos historiadores jesuitas formados desde la propia Compañía. Siguen existiendo, naturalmente, profesionales de la historia integrados en la orden, pero este palentino recibió el encargo de sintetizar y crear un camino, un relato histórico, en la misma línea de lo que habían realizado grandes nombres desde el siglo XVI. Se hallaba profundamente comprometido con el proceso de formación en la propia Compañía y así acudía a los cursos que le solicitaban desde sus superiores para hablar a los novicios de una u otra provincia, a los que estaban haciendo la tercera probación - los tercerones-, para dirigir

18 La figura del padre, y de la madre, se encuentra muy presentes en sus estudios, pero también en sus cartas: «Te escribo la víspera del día del Padre pues seguramente lo celebrarás mañana con María José y tus tres hijos. Es una fiesta llena de sentido humano y religioso. Ser padre de familia es una bendición de Dios y un honor. Y también un sacrificio, pero siempre compensado pues, aunque los hijos acaban dejando el nido familiar, siempre conservan las enseñanzas y el cariño de sus padres. Que Dios os bendiga y que os ayude a seguir edificando vuestra familia cristiana, tan necesaria en estos tiempos para la sociedad y la Iglesia» (Revuelta, 18.III.2017). 
tesis doctorales como aquella de Íñigo Arranz sobre la asistencia social de la Compañía en la provincia de Castilla en el siglo XVI o para presentar libros asociados a las grandes figuras del Instituto ignaciano. Se estaba preparando, como dijimos antes, para los 450 años de la muerte de san Ignacio de Loyola, a lo que se unía el quinto centenario del nacimiento de san Francisco Javier y del entonces beato Pedro Fabro. En estas conmemoraciones, Revuelta se sintió muy implicado y, además, sabía asociar y vincular a los demás en estas $\operatorname{tareas}^{19}$.

Nuestro historiador fue un magnífico profesor, con una gran capacidad docente y comunicativa. Carmen Labrador me confirmaba lo bien recibidas que fueron sus clases de Historia de la Iglesia en la Complutense de Madrid: catedrático de Historia Contemporánea de España en la Facultad de Ciencias Humanas y Sociales en la mencionada Universidad Pontificia Comillas. En la Complutense ejerció la docencia entre 1976 y 1985 y, con anterioridad, en la de Deusto entre 1970 y 1974. El 30 de septiembre de 2006 me comunicaba que ese era el último día de su «vida profesional activa. Mañana estaré ya jubilado. Es la salida de la última etapa [...] Me han propuesto para emérito, pero eso no significa que tenga clase». Nombramiento de profesor emérito de la Universidad Pontificia Comillas que llegó un mes después. Todavía habrían de faltar homenajes y presentaciones de sus últimas obras: "comprobé que tenías jesuitas muy mediáticos en la sala como Martín Patino y García de Cortázar, además del sacerdote Juan Mari Laboa», le escribí durante uno de ellos que le tributó su Universidad de Comillas (Burrieza, 29.XI.2011). Cuando le relaté el comienzo de mi vida docente en la Universidad de Valladolid en el curso 2010-2011, tras haber comenzado el contrato Ramón y Cajal, él me daba la visión de la evolución de un profesor a lo largo de una vida:

Las primeras clases son una experiencia reconfortante. Recuerdo que cuando yo empecé, sentía muchísimo perder una clase. Como cuando Don Quijote perdía un diente: «vale más un diente que un diamante», decía el caballero. Luego, con el tiempo, el entusiasmo no digo que se pierda, pero baja a posiciones más discretas. Y hasta te alegrabas de que una fiesta te hiciera perder una clase. Son cosas de la edad. Pero con esto no quiero quitarte el entusiasmo. Al contrario. Las clases siempre enriquecen al profesor bajo el punto de vista intelectual y humano.

19 «El viernes pasado [en septiembre de 2006] tuve una conferencia por enésima vez sobre las reducciones, en Madrid, en la residencia de Maldonado (antigua casa profesa). El día 20 hablaré a los antiguos alumnos de jesuitas en Chamartín; y el 26 en Burgos, donde conmemoran 50 años de aquel colegio. A unos y a otros les hablaré de la formación social de los alumnos jesuitas en el último siglo: del paternalismo al compromiso. Y en noviembre tengo que ir a Barcelona, a los 125 años de aquel colegio. A veces da la sensación que sólo se acuerdan de la historia con motivo de los centenarios», en Revuelta, Cantoblanco, 30.IX.2006. 
Y enseñar al que no sabe es una obra de misericordia, una gran oportunidad cristiana de imitar al Maestro en dar de lo que se tiene y en servir al necesitado ${ }^{20}$.

Confesaba que era un historiador que no sabía decir que no a los numerosos compromisos que brotaban y éstos, pues muchos queríamos disponer de su palabra y análisis autorizado, le impedían terminar los grandes horizontes de los que disponía, como el tomo tercero de mi Historia de la Compañía ${ }^{21}$ : «Luego los superiores me riñen porque no acabo de acabar lo que tengo que acabar» (Revuelta, 2.X.2006) ${ }^{22}$. Un encargo importante y oficial, en la línea de los que habían recibido en décadas anteriores Lesmes Frías o Antonio Astrain. Revuelta haya sido en España el historiador «oficial» más profesional de todos los que ha tenido la Compañía durante años, tan preocupada siempre por construir su discurso histórico porque, como pensaba el prepósito general Luis Martín en el siglo XIX — cuyas Memorias contribuyó a editar - el discurso histórico contribuía a definir a la propia Compañía de Jesús ${ }^{23}$. Fue el provincial de España, Pedro Ferrer Pi, el que en 1979 le

20 En esa misma carta firmada en Cantoblanco el 19 de septiembre de 2010 relataba el caso de dos alumnas japonesas que tuvo: «Discípulas ejemplares. Una es monja. Estudiaba teología; pero empezó el bienio preteológico y se apuntó a mi clase de Historia Contemporánea de España. Le di matrícula de honor, porque sabía más que sus condiscípulas españolas que (dicho sea de paso) eran bastante vagas. La otra - Chiaki Watanabe - estudiaba en la UNED, pero pidió asistir a mis clases, por libre. Se ve que la interesaban. Muy discreta, muy lista y muy agradecida. Cuando se despidió de mí, al volver al Japón, vi que llevaba una pequeña cruz de madera al cuello. ¿Eres cristiana? Soy catecúmena y me bautizaré al llegar a Japón. Así lo hizo. Volvió a España a defender su tesis doctoral, que le dirigió Feliciano Montero sobre Confesionalidad católica y militancia política: la Asociación Nacional de Propagandistas y la Juventud Católica Española (1923-1936). Está publicada en la UNED en 2003. Ahora Chiaki es profesora de una universidad de Japón y viene de vez en cuando a España a congresos».

21 Por entonces estaba proponiendo a Manuel Revuelta un libro acerca de la presencia de la Compañía de Jesús desde el siglo XVI hasta la entonces actualidad. Él mismo lo veía con cierta lejanía: «El libro que propones sobre la presencia de los jesuitas en Valladolid desde 1545 hasta hoy es un proyecto bonito y factible. Sería algo así como hacer para Valladolid lo que hicimos para España. Dejémoslo en proyecto y consultémoslo con la almohada. La condición indispensable sería tener garantía segura de publicación antes de empezar ese trabajo» en Revuelta, 2.X. 2006.

22 «Yo sigo estando muy ocupado. La semana pasada estuve en Barcelona, dando unas conferencias a los padres mercedarios; y esta tarde tengo ir a ICADE a tener dos charlas a seglares afectos o colaboradores de la Compañía», en Revuelta, 11.XI.2011.

23 Memorias del P. Luis Martín, General de la Compañía de Jesús (1846-1906), editada en 1988 por J.R. Eguillor, M. Revuelta y R. M ${ }^{a}$ Sanz de Diego. Revuelta explicó muy bien la evolución historiográfica que había desarrollada la Compañía de Jesús restaurada en España, desde 1815 y hasta aquel momento presente en 2017, cfr. 
destinó a investigar primero y escribir después la Historia de la Compañía en estas tierras:

[...] meterse en una obra de esa envergadura significa entrar en un túnel del que no sabes cuándo vas a salir —escribía en sus Memorias de los últimos días-. Ocupa todo el tiempo y toda la vida. Los estímulos, por otra parte, fueron escasos dentro de la Compañía, al menos no alcanzaron el nivel que yo esperaba. Tengo que constatar, sin embargo, que no faltaron recursos económicos en forma de ayudas a la investigación de la Universidad de Comillas. Yo seguí la historia que había dejado en 1868 el P. Lesmes Frías en dos tomos sobre la Compañía restaurada. Redacté una historia minuciosa y total que exigía conocer todo lo que se había escrito sobre la Compañía Restaurada — que no era mucho—y además y sobretodo consultar todos los archivos disponibles de España y Roma. Propiamente escribí cuatro tomos que llenan unas 4500 páginas [...] La consulta de los archivos fue fundamental. En España trabajé en Sant Cugat, Barcelona, Loyola y Alcalá de Henares [...] El archivo de la Curia de Roma (ARSI) es imprescindible, porque llena todas las lagunas de los archivos de España. La primera vez que estuve en Roma, para trabajar en ARSI fue en 1979 y la segunda en 1988. Cada vez encontraba menos facilidades [...] Los dos primeros tomos se presentaron en la Biblioteca Nacional. El último ni siquiera tuvo los honores de la presentación. Lamentable [...] La excusa es que durante el periodo que yo estudio, que son los 44 años que van de 1868 a 1912, se realiza la verdadera restauración de la Compañía contemporánea, con las casas y obras más importantes que hoy todavía perduran. Es, por tanto, obligado estudiar con detalle ese período. Todo lo demás es repetición o complemento. [Memorias de Manuel Revuelta en Necrológica por Antonio Pérez, SJ] $]^{24}$

De alguna manera culminación de todo ello fue el centenario de la Restauración de la Compañía de Jesús en la Iglesia y en España, doscientos años después de aquellas fechas de 1814-1815: "Yo sigo preparando mi librillo sobre el restablecimiento en la Compañía. Tendré que interrumpir el trabajo unos días, pues a principios de junio [2013] iré a San Sebastián a dar el cursillo a los novicios» (Revuelta, 23.V.2013). Fue un tiempo de una actividad desbordante, quizás el último periodo de estas características en su vida, cruzando incluso el Atlántico, con sendos congresos internacionales en

Revuelta, M., Historiografía de la Compañía..., ob. cit., pp. 301-326. Él mismo me la remitía el 6 de septiembre de 2017, con una carta autógrafa que conservó en la propia separata dentro de mi archivo.

24 Lo que denominamos Memorias de Manuel Revuelta es un texto inédito que escribió en los últimos meses de su vida. Parte de ellas se encuentran en la necrológica que firmó el padre Antonio Pérez García el 20 de julio de 2019. No hemos podido consultar el texto que sería necesario conocer en su totalidad [las Memorias], antes de que reposasen durante años en un Archivo. 
Bogotá (agosto 2013) y México (noviembre 2013) ${ }^{25}$. Cuando regresó confesaba «corregir de prisa» las pruebas del libro El restablecimiento de la Compañía de Jesús (Revuelta, 2013). Lo habría de publicar ediciones Mensajero. Eran aquellos, también, días de reestructuración de la tercera Compañía, la posconciliar o renovada como él mismo la denominaba, pues todas las provincias españolas se habrían de unir en la nueva Provincia de España ${ }^{26}$. En esa Navidad aparecía esta obra definitiva ${ }^{27}$, en compañía de otra sobre la expulsión firmada por José Antonio Ferrer Benimelli (Ferrer Benimelli, 2013). Quizás aquel activismo le empezó a pasar cierta factura física e intelectual al profesor Revuelta. Habitualmente se llamaba «viejo amigo jesuita» en la correspondencia y, a finales de 2015, empezó a tener algunos achaques de salud. Él mismo lo confirmaba: «tengo que moderar el ritmo de trabajo». Estaba a punto de cumplir, el $1^{\circ}$ de enero de manera puntual, sus ochenta años.

Sin embargo, la sucesión de títulos y de inquietudes parecían no demostrar todo ello. El gran diarista de la Compañía expulsada, disuelta y restaurada, Manuel Luengo, no podía escapar de su interés. En ese trabajo, se unía a lo mucho que habían realizado los mencionados compañeros de la Universidad de Alicante desde los libros de Enrique Giménez; la tesis doctoral y la labor editorial que había efectuado Inmaculada Fernández Arrillaga; sin

25 "Fui unos de los tres "conferencistas" (como allí dicen), que abrieron las sesiones en las que participaron unos veinte ponentes, casi todos sudamericanos. Muy interesante el congreso, la ciudad y el ambiente. Acabo de llegar hoy, cansado pero contento [...] Enriquece mucho ver tierras y gentes distintas; pero gusta volver a casa» (Revuelta, 10.VIII.2013).

26 «El día 21 [de diciembre de 2013] iré a Villagarcía a la reunión que suele celebrarse allí antes de Navidad, para los jesuitas de la Provincia de Castilla que quieran asistir. El Provincial me encargó que tuviera una charla que versará sobre: Las ocho Provincias de Castilla en la Compañía restaurada (1863-2014). Es como la despedida de la Provincia de Castilla, que formará, con las demás la Provincia de España que se formará el año que viene» (Revuelta, 3.XII.2013).

27 «Hoy, después de la misa de las monjas [era capellán de las Hijas de la Caridad] se me acerca una de ellas para hablarme de un artículo mío en Ecclesia. Le dije que no había escrito ningún artículo. Entonces me trajo la revista y vi de qué se trataba: tu espléndido artículo sobre la restauración de la Compañía, con buena información, buen estilo periodístico, buenas ilustraciones. Y con referencias a tus amigos historiadores: entre los que veo citado al "gran" MRG, del que dices que lo sabe todo sobre la restauración, y que va de cátedra en cátedra a modo de misionero popular. Yo no había reparado todavía en el último número de Ecclesia, así que recibí una grata sorpresa. Una vez más te muestras especialista de la Compañía, con un afecto que ya quisiéramos los mismos jesuitas. No me extraña que te confundan con uno "de los NN". Recibe pues mi doble agradecimiento por la referencia personal en el artículo (con la exageración debida a tu amistad), y el favor que haces a la Compañía con tus trabajos históricos, a todos los niveles» (Revuelta, 6.XII.2014). 
olvidar la integración de uno de los historiadores más jóvenes y competentes que han analizado la expulsión, Carlos Martínez Tornero ${ }^{28}$. Fue un importante esfuerzo editorial de varias Universidades, la de Alicante y la Pontificia Comillas, en torno al final del monumental diario, las páginas que correspondían a 1814 y 1815 , en torno al final del destierro y la restauración de la Compañía de Jesús, de la mano autorizada de Manuel Luengo. El proyecto comenzó en abril de 2013 y culminó dos años y medio después. Anteriormente, Fernández Arrillaga también había trabajado con el mencionado Isidoro Pinedo para editar el año del Diario relativo a la extinción de la Compañía, el de 1773, concluido en diciembre de 2012.

\section{UNA CONTINUADA FUENTE DE INFORMACIÓN}

Manuel Revuelta era una fuente continuada de información procedente del $\operatorname{archivo}^{29}$, hombre constante y permanente ${ }^{30}$. Estaba editando una antolo-

28 «He recibido vuestro tomo de Luengo, el último de la serie y donde os habéis unido con gran acierto los tres para enseñarnos y anotarnos cada detalle y las pistas esenciales de este texto que nos seguirá iluminando sobre las percepciones de un jesuita exiliado, sobre todo en el ocaso de su vida y en el momento de la restauración de la Compañía de Jesús» Burrieza, 27.XII.2015. Cfr. Fernández Arrillada, I y Martínez Tornero, C. (eds.) (2015) y estudio introductorio de Manuel Revuelta, Diario de 1814 y 1815. El final del destierro y la restauración de la Compañía de Jesús. Manuel Luengo, SI.

29 "Yo estuve en Roma en octubre [de 2009], como creo que te dije. Vine muy contento de la conferencia inaugural que tuve en el congreso de los agustinos; y no tan contento del ARSI, donde no me dejaron sacar ni una fotocopia (por estar en un momento de reajuste, según me dijeron)» (Revuelta, 2.XII.2009).

30 «Te ha salido un buen artículo periodístico sobre el papel de los jesuitas en la Iglesia y en la historia [se refería al publicado en Ecclesia con motivo de la elección del padre Adolfo Nicolás]. Has ido planteando los puntos clave y polémicos, exponiéndolos y resolviéndoles desde una perspectiva positiva y a mi juicio, objetiva. Con el aliciente de aludir a no pocos tópicos, que quedan debidamente matizados. Partes del significado de la vida de Ignacio. Enfocas el tema de la contrarreforma en el sentido de una reforma que debe empezar por la conversión personal. Matizas bien los conceptos de obediencia y milicia. Afrontas, con el aliciente de las definiciones del diccionario, lo que hay detrás de la llamada hipocresía jesuítica (con el dulce monjil de los jesuitas, que pone un toque de sabor popular). Hablas de contrastes y contrapesos en la manera de actuar (modo nuestro de proceder), como el buscar a Dios en el mundo. Aludes al dinamismo de los métodos apostólicos, a la vocación misionera inculturizante, a las paradojas políticas de unas víctimas tanto de absolutistas como de liberales, y, en fin, a la unidad y diversidad hasta el momento presente de la 
gía de textos acerca de la Semana Santa de Valladolid y me apareció una poesía del padre Alberto Risco que se titulaba La mantilla en el templo: «¿Sabes algo de este jesuita?», le escribí. Ese mismo día de finales de enero de 2008 respondía, apoyándose en los nuevos materiales del entonces Diccionario Histórico de la Compañía de Jesús, con su contexto y trayectoria biográfica, con sus aportaciones hasta su muerte en Valladolid, en pleno nacionalcatolicismo, con un libro de autoría del padre Risco La epopeya del Alcázar de Toledo (Revuelta, 30.I.2008). Si escribías sobre la Compañía y la percepción de la mujer, él mismo te proporcionaba el decreto de la Congregación XXXIV (1995) titulado La Compañía y la situación de la mujer en la Iglesia y en la sociedad ${ }^{31}$. Si necesitabas saber dónde se encontraban los libros del antiguo colegio de la Compañía de Medina del Campo, el fundado en 1551, él relataba que en la biblioteca de la Universidad de Comillas los había de aquella procedencia, comprados antes de 1931. Fueron fichados los volúmenes en un trabajo que realizaron los técnicos del Patrimonio Nacional, pudiéndose haber hecho referencia a su procedencia si existía constancia del mismo: «no hay un catálogo o inventario específico de los libros que vinieron de Medina, según me ha dicho el bibliotecario saliente, Padre Eusebio Gil, que estos días ha sido sustituido por una nueva bibliotecaria, la Dra. Henar Pizarro, historiadora, con la que tengo plena confianza y nos dará todas las facilidades para las consultas o trabajos que queráis hacer»(Revuelta, 2.X.2005).

Correspondencia que servía para estar al día de las novedades en la historiografía jesuítica, sin olvidar los congresos y reuniones científicas ${ }^{32}$. Bas-

elección del nuevo P. General. La verdad es que no se puede decir más en menos. Es un artículo muy logrado» (Revuelta, 22.I.2008).

31 «En el citado libro, el decreto $\mathrm{n}^{\circ} 14$ es el que titulas correctamente "La Compañía y la situación de la mujer en la Iglesia y en la sociedad". Le precede una breve introducción de Darío Moyá (Provincial de Aragón) en pp. 303-305, a la que sigue el texto del decreto, pp. 306-313. Si necesitas fotocopia te la mando enseguida», en Revuelta, 23.X.2004.

32 «Me escribe el P. José del Rey, de Venezuela, pidiéndome datos y fecha de las conferencias que van a organizar en la Casa de Velázquez en enero, pues es posible que él esté por entonces en España y le gustaría asistir si pudiera. Creo que tú me hablaste de ello y me dijiste que tendrías una ponencia sobre misiones jesuíticas. El P. Del Rey parece que piensa que el tema versará sobre misiones de la Compañía; yo creo es de misiones en general. En fin, que si tienes datos sobre el temario y fechas exactas; y sobre todo si tienes el programa y me lo puedes mandar para remitírselo yo a Del Rey, te lo agradeceré mucho», Revuelta, 28.XII.2006. "Muy gustoso te envío el programa del coloquio de la Casa Velázquez. Efectivamente, es sobre misiones: "Circulación de saberes y Misiones" pero no reducido a la Compañía de Jesús. A mí me toca hablar de la formación de los misiones para Inglaterra. He visto que irá el padre Borja Medina o el padre Melià»(Burrieza, 28.XII.2006). 
taba con una leve asociación, por ejemplo, a las reducciones del Paraguay, para conocer que el padre Martín Morales - al que tuve el placer de conocer muchos años más tarde en una tesis doctoral en la Universidad de Alicante, en el verano de 2019- había inaugurado una nueva serie de la Monumenta Historica Societatis Iesu con el significativo título de A mis manos han llegado. Cartas de los Padres Generales a la Antigua Provincia del Paraguay (1608-1639) (Revuelta, 20.XI.2005): «Martín Morales es argentino, director actual del Instituto Histórico, y muy enterado de las reducciones sobre las que hizo la tesis doctoral. Al volumen publicado seguirán otros dos sobre Paraguay» ${ }^{33}$. Este de las reducciones era uno de los temas que le interesaron verdaderamente y donde no faltaron sus aportaciones. Mencionaba, en cierta ocasión, el interesante artículo que había recibido del padre Carbonell de Massy, jesuita de la Gregoriana, especialista en los asuntos económicos de estas misiones, publicado en la revista Pasquisas, páginas que le habían servido para matizar algunos «tópicos o visiones demasiado rectilíneas con que a veces tratamos el tema de las reducciones. Si no lo tienes te lo puedo mandar por correo» (Revuelta, 27.VI.2006).

Siguiendo la misma línea y metodología de aquel libro que había realizado acerca de la Iglesia española en el siglo XIX (Revuelta, 2005). Revuelta reunió numerosos trabajos que sobre los jesuitas había ofrecido en numerosas revistas científicas. Aprovechaba unas palabras de Ignacio de Loyola, «Servir a todos en el Señor. Once calas en la Historia de la Compañía de Jesús» ${ }^{34}$. Al

${ }_{33}$ En una nueva carta, precisamente la segunda que me escribió un 20 de noviembre de 2005 [«no quiero dejar para mañana lo que puedo hacer hoy, fiesta todavía de Cristo Rey, aunque es de noche»], me hizo un análisis de las aportaciones del mencionado Martín Morales: «Martín Morales publicó un largo extracto de su tesis doctoral que supongo conocerás, titulado Los comienzos de las reducciones en relación con el Derecho Indiano y el Instituto de la Compañía de Jesús. Evolución y conflictos: Archivum Historicum SI, t. 133 (1998). Me resultó interesante, aunque un tanto discutible pues adopta una postura bastante crítica en relación con la supresión del servicio personal por el P. Diego de Torres Bollo. En la introducción del tomo de las cartas de los Generales mantiene la misma tesis, aunque algo más matizada. Los puntos de observación de los documentos publicados están sobre todo en Roma y Paraguay, pero no faltan abundantes referencias a España, jesuitas españoles y castellanos» (Revuelta, 20.XI.2005).

34 "Quidquid recipitur ad modum recipientis recipitur. Recibes mis cosas en vaso de Amistad y queda todo amoldado a tu benevolencia. Es lo que pasa con las «Once calas». Pero en fin, todo ayuda y reconforta y se agradece el aprecio que demuestras en esta ocasión, como siempre, de manera sincera por tu parte [...] Las calas que te mando son, como su nombre indica, calas; por tanto quedan muchos vacíos y no me meto en profundidades; pero en conjunto creo que cumplen el fin que se pretende, que es ofrecer una selección de temas históricos escogidos que iluminan la historia 
material publicado, el historiador sumaba trabajos inéditos, procedentes de conferencias. La fecundidad intelectual de Revuelta se unía a su capacidad analítica. Con todo, su muerte, además de dejar un vacío enorme desde lo personal, ha permitido comprobar que numerosos son los caminos abiertos. Recuerdo que cuando le remití, en el otoño de 2007, la conferencia que me habían solicitado en la parroquia vallisoletana de Nuestra Señora del Pilar, con motivo del centenario de su construcción, él me subrayó notablemente el papel del padre Marcelino de la Paz. Curiosamente, meses después de su muerte, he prologado una monografía que Manuel de los Reyes ${ }^{35}$, un consumado especialista en la Casa Social Católica en Valladolid ha publicado en 2019 en ediciones Encuentro, y donde ha destacado el protagonismo pastoral de este jesuita que fallecía en el momento de la disolución de la Compañía en España en 1932.

Con Revuelta estaba próximo aquel que te enseña a caminar con seguridad y a compartir las alegrías. Afortunadamente he dispuesto de miradas privilegiadas de los que me han enseñado mi profesión con dedicación. Cuando recibí el Premio de Investigación Provincia de Valladolid en diciembre de 2005, tras la tesis doctoral, por el libro Valladolid, tierras y caminos de jesuitas, este historiador jesuita respondió con la percepción de aquella máxima ignaciana, "gaudere cum gaudentibus». "Comparto como amigo tu satisfacción por el premio bien merecido, y me alegro como jesuita con el tema» (Revuelta, 29.XII.2005). Después estaba la publicación y no fue difícil de convencer a Manuel Revuelta para que él escribiese el prólogo de aquella obra $^{36}$. Era uno de los mejores prologuistas y autores de recensiones que he conocido, precisamente por esa mencionada capacidad de análisis y de lector profundo. A la presentación del mismo, a finales de marzo de 2007, asistió el propio Revuelta recordando la ciudad del Pisuerga en la que había vivido:

Valladolid, bajo la lluvia, me hizo revivir recuerdos de muchas cosas en las pocas horas que pasé allí. Esta mañana pasé por el colegio [de San José]. Pocas veces he sentido tan claramente la sensación de que uno es ya de otra edad y otro

general de la Compañía y su ideal primitivo de "servir a todos en el Señor"» (Revuelta, 27.VI.2006).

35 Manuel de los Reyes fue un común amigo que conocimos al mismo tiempo, que nos aportó mucho al conocimiento de la obra social de la Compañía contemporánea.

36 «He redactado el borrador del prólogo que me pediste, que es breve, como deseabas. Me he servido de las notas que tenía sobre tu tesis y del repaso rápido a los dos primeros capítulos que, según me decías, formarán el libro que preparas. Como parece que te urgía el prólogo, para poder presentarlo en la imprenta, he adelantado tu encargo y ahí te va lo que ha salido. A ver si me das un aprobado, aunque sea ramplón. Es borrador, por tanto, corrige sin contemplaciones los defectos que encuentres e indícame todas las sugerencias que creas oportunas» (Revuelta, 12.X.2006). 
tiempo. Me abrieron la capilla, pues estaba cerrada con llave. Está perfectamente restaurada pero vacía. Es un museo. La utilizan solo en las bodas. La capilla era el centro neurálgico del colegio de hace cincuenta años. Yo no quiero hacer comparaciones con lo de antes y lo de ahora. Solo digo y siento que yo soy de antes. Con eso, y con los recuerdos de tantas personas queda uno con una sensación de nostalgia por las cosas, que son y no son las mismas: "Hoc est illud». Esto es aquello, sí; pero ¿esto es aquello? "Sunt lacrimae rerum»: digamos que es una nostalgia consoladora, un «cauterio suave». (Revuelta, 27.III.2007)

\section{CAMINAR CON PIE FIRME}

Como colofón a su libro Enigmas históricos de la Iglesia española contemporánea (Universidad de Comillas, 2017) se incluía una lista minuciosa de las cuatrocientas ochenta y dos publicaciones de Manuel Revuelta. Todavía había que sumar algunas páginas, por ejemplo, las de la obra coordinada por Francesc Joan Monjo, Jesuïtes valencians (Alicante, 2018). Y aunque Revuelta se empezaba a resentir físicamente y se confesaba en una dedicatoria como un «historiador en retirada», siempre caminó con pie firme en su autoridad intelectual y con una gran fuerza de voluntad. Antes, al ponerse en marcha la realización del Diccionario Biográfico Español por parte de la Real Academia de la Historia, de la sección de la Iglesia se encargó César Ramos, un extraordinario coordinador que procuró que en este caso todas las órdenes religiosas estuviesen convenientemente representadas a partir de los avances de sus respectivas historiografías. Revuelta mostró interés por esta obra, confesaba que había escrito nueve biografías o entradas, pero restaba mucho por hacer. En total, como indicará José García de Castro, entregó dieciséis:

[...] de lo contrario no podría haber hecho otra cosa en un año, por lo menos. Pero le indiqué [a César Ramos] otros historiadores o expertos jesuitas con sus direcciones y las biografías que podrían escribir. De esto ya tienes noticia pues recordarás —continuaba - que incluí al padre Luis Fernández y con este motivo me diste buena información. Me indicas tres que, al parecer, no tienen autor: Iparraguirre, Egaña y Llanos. Es claro que no deben faltar. De los dos primeros se podría encargar el P. Ignacio Echarte, historiador, provincial que fue de Loyola y ahora residente en la curia de Roma. Y la de Llanos la podría escribir el P. Alfredo Verdoy, historiador, exprovincial de Toledo y ahora rector en Salamanca, que acaba de escribir un breve libro sobre El Pozo del Tío Raimundo ${ }^{37}$. (Revuelta, 20.XI.2005)

37 Sobre Llanos, en estos años publicó un libro bien interesante Pedro Miguel Lamet. Alfredo Verdoy fue alumno de Revuelta, pues algunos de los novicios estudiaron 
El Diccionario ha sido una enorme empresa. A César Ramos lo conocí a través de la mencionada Inmaculada Fernández Arrillaga, por el encargo de la biografía de Isabel Roser, mujer del siglo XVI que quiso una rama femenina de la Compañía de Jesús. Revuelta no se consideraba en el momento adecuado para culminar estos horizontes biográficos para los cuales, por su minuciosidad, se encontraba altamente capacitado. Debía culminar importantes obras. Trazó con maestría tantas trayectorias vitales, pero había tenido una costosa trayectoria en lo que se refería, como perito histórico, en el proceso del padre Francisco Butiñá, colaborador de la fundadora de las Siervas de San José, hoy santa Bonifacia Rodríguez ${ }^{38}$. En aquella empresa, esa minuciosidad le había arrojado a un trabajo solitario. Eso sí, todos los que nos embarcamos en la realización de muchas de estas biografías relativas a jesuitas en el Diccionario Biográfico Español tuvimos que recurrir a las fuentes de información aportadas por este historiador. Incluso, había estudiado el relato que el padre Luis de Coloma había escrito, a modo de cuento, del Ratón Pérez, dedicado en aquel caso a Alfonso XIII, el rey-niño, con una edición muy especial que nos descubrió la peculiar personalidad de este novelista que encontró su vocación tardía en la Compañía ${ }^{39}$.

Existieron dos importantes retos que emprendí con el consejo de nuestro jesuita. "Se ha puesto en contacto un profesor de Historia Contemporánea de Valladolid -le relataba en julio de 2010 - para proponerme un estudio sobre el colegio de San José de Valladolid en los años de la República y del exilio en Portugal. Por lo poco que me han dicho - estamos pendientes de

historia en la Universidad Autónoma de Madrid, donde también realizó el doctorado con una tesis sobre los bienes de los jesuitas durante la supresión e incautación realizada a la Compañía durante la Segunda República. Una gran obra, así calificada por Revuelta, publicada por la editorial Trotta. Cuando fue provincial de Toledo, se unieron las provincias de Castilla y Toledo. Tras haber sido rector en Salamanca, volvió como profesor de Historia de la Iglesia a Comillas y en 2020 es el director del Archivo de la Compañía en Alcalá de Henares.

38 «Acabo de recibir separatas del artículo sobre el P. Butiñá, que publiqué en Miscelánea Comillas hace unos años, y Teófanes lo ha publicado de nuevo en el último número de Estudios Josefinos. Aunque ya conoces el artículo, pues me parece que te envié fotocopia, te puedo mandar una separata de esta segunda edición, a la que parece seguirá una tercera, pues quieren publicarla las Siervas de San José, con las conferencias que se tuvieron en Salamanca con motivo del centenario de Butiñá», (Revuelta, 28.I.2008). Cfr. Revuelta (1999). También fue publicado este trabajo en Estudios Josefinos, no 122 (2007), pp. 185-238. En el Diccionario Biográfico Español la entrada de Butiñá no la realizó Revuelta sino Jesús Martín Tejedor.

39 Buscando a Ratón Pérez. Estudio del Cuento Infantil del P. Luis de Coloma SJ, por F. Climent, M ${ }^{\mathrm{a}}$ J. Gómez-Navarro, A. Muñiz y M. Revuelta, 2002; Ratón Pérez. Cuento Infantil por el P. Luis de Coloma, Madrid, 1911 (edición facsímil 2002). 
una reunión - hay un proyecto financiado por el CEU sobre este tema. Han visto la historia que hice del Colegio de Lourdes de los Hermanos de la Salle y se han fijado en cómo traté el tema de la República, pues el colegio de Lourdes tiene otra solución con respecto a los jesuitas. Ya te iré contando pues tú me puedes aconsejar»(Burrieza, 10.VII.2010). En aquellos momentos, se estaba reeditando una de sus obras primeras, La Exclaustración, ahora publicada fuera del ámbito de la BAC como lo hizo inicialmente y gracias al CEU madrileño ${ }^{40}$. También había intensificado el ritmo de mi libro sobre las salesas en Valladolid, fijándome en lo mucho que había dicho Revuelta sobre la Compañía, las visitandinas y la devoción al Sagrado Corazón de Jesús (Revuelta, 12.VII.2010). Al conocer el proyecto que me habían ofrecido sobre el llamado «Colegio de Curía», se mostró muy receptivo exponiéndome los nombres fundamentales para analizar aquella extraordinaria experiencia educativa y pedagógica protagonizada por un grupo de jesuitas en los difíciles años treinta.

Fundamental resultaba conocer la obra que había sido escrita por el padre Enrique Herrera Oria, el manual de todo ello: «el principal promotor de estos recuerdos de Curía — argumentó Revuelta- es el P. Juan Lamamié de Clairac, que vive en (el colegio de) San José, a quien deberás consultar y pedirle que te dé todas las noticias que tenga. Estoy seguro de que te ayudará con mucho gusto, sobre todo si le dices que vas a escribir sobre el tema» (Revuelta, 12.VII.2010). Después Lamamié, que había sido maestrillo suyo y profesor de latín en segundo de bachillerato en los años cuarenta, fue trasladado a la enfermería de Salamanca: «su entusiasmo es incombustible pero los años se le notan». Precisamente, al visitar y entrevistar en tantas ocasiones al anciano padre Lamamié de Clairac - aunque lo conocí en Valladolid-, fue cuando por vez primera entré en la casa de la Compañía del paseo salmantino de San Antonio, donde vivió sus últimos meses nuestro historiador jesuita. Eso sí, a medida que se iniciaba el proyecto, Revuelta me advirtió su preocupación sobre la edición de una obra con esta temática. A su juicio, era menester prestar mayor atención para su publicación, a los títulos de las monografías que se estaban elaborando sobre la historia de la Compañía, no solo desde las universidades sino muy especialmente desde el propio grupo editorial ignaciano. Me ponía el ejemplo, en 2010, de la biografía que había concluido el musicólogo jesuita José López Calo sobre Nemesio Otaño (López Calo, 2010), título no aceptado por la Universidad Comillas a pesar de su recomendación y de que Otaño había sido el fundador de la Schola Cantorum. Para el libro que elaboré del Colegio de Curía, finalmente fue el

40 Revuelta (2010). La edición de la BAC era de 1976. 
entusiasta editor Carlos García Costoya, propietario de Xerion Ediciones ${ }^{41}$, el que abordó su publicación con la Asociación de Antiguos Alumnos de Curía, precisamente con el prólogo de Manuel Revuelta. No podía haber en este asunto otro introductor mejor. Además, él había conocido a muchos de los que protagonizaron no solamente la experiencia de Curía sino también la previa disolución de 1932 como aquel hermano Sobrón que, contra viento y marea, mantuvo abierto su colegio en Valladolid ${ }^{42}$.

De nuevo, Revuelta facilitaba los caminos que se abrían en una investigación como esa. Si había que recurrir a los que antes investigaron y pertenecían a la Compañía, con él resultaba fácil. En la experiencia pedagógica de Curía había tenido gran importancia el Colegio de Apóstol Santiago de Vigo y los jesuitas de Galicia, estudiados desde el contexto del siglo XVI por Evaristo Rivera ${ }^{43}$. Pero también uno de los alumnos que habían sido del

${ }^{41}$ Desde Xerion habría de salir otro interesante trabajo de Manuel Revuelta en la obra coordinada por W. Soto (2018): Diego de Pantoja (1571-1618), un puente con la China de los Ming, «Los ritos chinos y jesuitas según la documentación franciscana», pp. 149-197.

42 «Me ha gustado oírte hablar [se refería a una conferencia en el Ateneo de Valladolid] del P. Encinas y del P. Cid y sobre todo del Hermano Sobrón, Don Teótimo, y de su escuela del Arco del Ladrillo. Don Teótimo fue mi profesor de ingreso de Bachillerato, en el primer año que estuve en Valladolid, siendo un niño de 9 años, curso 1945-46. Teníamos las clases de ingreso en la casa donde comenzó el colegio, contigua a las ruinas todavía existentes de la iglesia de San Juan. El H. Sobrón era muy amigo de mi padre, que le llevaba trigo para las palomas que tenía en una especie de palomar. Desde entonces estuve muy enchufado, y ascendí de la calle de la Maruquesa a la calle de Santiago (que tenía pupitres individuales para los más listos). Me dio luego muchos premios y me sacó fotos ampliadas, porque era buen fotógrafo. Me llamó la atención la buena asistencia de público a tu conferencia, en la que utilizas con maestría el power point, con fotos muy interesantes sobre el colegio» (Revuelta, 24.II.2013).

43 «He pensado que es posible que haya información sobre Curía en el Colegio de Vigo, donde el P. Evaristo Rivera reunió papeles sobre la Compañía en Galicia. Ahora el P. Rivera está ya retirado, pero le ha sustituido el P. Manuel Cabada que ha sido profesor de Filosofía en Comillas y en la Complutense hasta que se jubiló y cambió su residencia de Cantoblanco al Colegio Apóstol Santiago de Vigo. Le acabo de escribir preguntándole si hay allí fondos de Curía» (Revuelta, 30.XI.2012). «El Padre Evaristo Rivera está retirado en Salamanca. No tiene email. En el catálogo pone: "ora por la Iglesia y la Compañía, cuida su salud". Te atenderá bien si te pones en contacto con él, aunque no sé si será posible dado su estado de salud. Es gran persona, fue hombre de gobierno (rector y socio del Provincial) y muy buen historiador de la Compañía, y muy gallego, en el mejor sentido de la palabra. Su tesis doctoral se publicó en el libro que sin duda conoces Galicia y los jesuitas, sobre los colegios de la antigua Compañía. Después publicó la historia del colegio de Vigo» (Revuelta, 3.XII.2012). "Hoy he venido de Palencia (reunión de La Tello); y la semana pasada estuve en Salamanca, dando 
balneario-colegio portugués, y sin proceder de colegios de jesuitas, había sido el catedrático Vicente Palacio Atard. Así, en los días que era imposible tener abierto un colegio de la Compañía en la España republicana, estas aulas se establecieron en los balnearios construidos en los años veinte y que durante el invierno se hallaban vacíos. Palacio Atard, que había sido el director de la tesis doctoral de Revuelta -Política religiosa de los liberales en el siglo XIX. Trienio Constitucional (1972) - no olvidaba en un libro de homenaje que se le dedicó, aquel curso de joven estudiante en el que viajó a Portugal (Palacios Bañuelos, 2013, pp. 30-36). Precisamente, cuando por vez primera participé en 2013 en el Máster Ignaciano y residía en la Residencia de Profesores, recuerdo que coincidió con el fallecimiento de este catedrático que también había sido profesor de la Universidad de Valladolid. Revuelta acudió al cementerio a rezar el responso tal y como se lo solicitó la familia.

En noviembre de 2015, nuestro historiador jesuita recibió el primer borrador de este libro de Curía para la elaboración del prólogo, mientras la Asociación de Antiguos Alumnos debatía sin tregua el posible título o la fotografía que habría de definir la portada. «Yo ya solo valgo para prologuista -indicaba en una carta de aquellas fechas con cierta pesadumbre de ánimo-. Creo que he escrito 28 prólogos, de los que 10 han sido para libros sobre colegios de jesuitas. El disco ya está algo rayado. El último prólogo fue para Cristo Rey de Valladolid [...] El ultimísimo prólogo — que hará el número 29- será el tuyo de Curía. A ver cómo sale» (Revuelta, 10.XI.2015). En la peregrinación editorial fueron proféticas las advertencias pasadas de Revuelta, aunque su prólogo solo tardó catorce días en llegar: «puedes enviárselo al P. Clairac (Juan Lamamié) a ver si lo aprueba» (Revuelta, 24.XI.2015)44. Sus palabras fueron muy apreciadas, contaban con autoridad. Días después viajaba a Cantoblanco a impartir el habitual Máster Ignaciano. Allí hablamos de «algunas erratas y comentarios de cosas accidentales» como las definía con generosidad y que había encontrado en el manuscrito. Al mismo tiempo, en esa labor de lector empedernido, se había empapado de mi última obra sobre monjas carmelitas en coincidencia con el quinto centenario del nacimiento

el cursillo de marras a los tercerones sobre supresión y restauración de la Compañía. En la enfermería vi a varios antiguos compañeros, algunos muy deteriorados en su salud; por ejemplo, el P. Evaristo Rivera, casi imposibilitado, incluso de hablar. Me acordé de tu deseo de hablar con él sobre Curía, pero tal como está resulta desaconsejable. Por allí andaba el P. Juanito Clairac, que aunque le cuesta moverse, está bien de cabeza» (Revuelta, 22.II.2013).

44 «La semana pasada estuve en Salamanca a dar el cursillo de marras a los tercerones. Allí vi al P. Clairac que espera con ilusión tu libro sobre Curía», en Revuelta, 23.II.2016. 
de Teresa de Jesús — precisamente, lectoras y escritoras_-, remitiendo a Estudios Eclesiásticos con Santiago Madrigal la pertinente recensión ¿Se podía pedir más? Así era la generosidad personal e intelectual del padre Revuelta.

En febrero de 2016, impartió el curso para los jesuitas de la Tercera Probación. Demostraba en los últimos meses una salud "renqueante», lo que condujo a pensar al superior de su comunidad de Comillas que era necesario que viajase temporalmente a la enfermería de Salamanca. Comenzó a aparecer en el horizonte de Manuel Revuelta si debía trasladarse a vivir a la Ciudad del Tormes, donde llamó a la puerta para ser jesuita: «de todos modos, Salamanca sería para mí la mejor casa en el caso de que tuviera que dejar Madrid [...] Llevaré ordenador y móvil» (Revuelta, 12.V.2016). La decisión a mí me impresionaba pues no quería aceptar que aquel jesuita tan querido no solo se estuviese haciendo mayor, sino que además en él, la enfermedad, pudiese encontrarse patente. Antes de que esto sucediera recibimos aviso de que uno de los más deseosos receptores e impulsores de aquel libro de Curía había fallecido precisamente en Salamanca —un 27 de abril de 2016-. Era el peculiar espíritu del padre Lamamié, el último de los jesuitas de aquella familia numerosa y levítica, cuyo padre diputado defendió con énfasis en las Cortes de la República la pervivencia de la Compañía en España. Finalmente, la imprenta ofrecía Curía, un Colegio en el exilio ${ }^{45}$ antes de la Navidad de 2016 y era presentado este libro en marzo de 2017 donde había que hacerlo, en el Colegio de San José de Valladolid. Cuando Revuelta contempló el video de aquel acto, se atrevió a escribirme, «lástima que se echaran de menos precisamente los jesuitas». Eso sí, en el acto no faltaron el director seglar del centro y el delegado de la Compañía para con estos colegios. La situación había cambiado con respecto a otros tiempos. Parecía que hablar de la Compañía en los días de la República no resultaba políticamente correcto. Tras el «chequeo» salmantino, Revuelta regresó a Madrid. Él seguía trabajando a otro ritmo y con un espíritu un tanto de recogida. Le quedaba celebrar sus bodas de oro en el sacerdocio, recordando aquel 14 de julio de 1966, en Valladolid.

Nunca olvidaré tampoco la lectura, tan llena de propuestas, que realizó en los últimos meses de 2018, antes de abandonar Cantoblanco, al último libro que me conoció escribir, que no publicar. El último publicado se refería a un homenaje que, con trabajos sobre Valladolid, pude preparar a mi maestro

45 «Hoy me ha llegado el libro de Curía. Precioso. Aunque lo esperaba, me ha hecho mucha ilusión. Enhorabuena. Supongo que les gustará a los AA [...] Ha quedado bien el aspecto del libro y has salido muy guapo en la foto, con cara de intelectual y yo diría que incluso con cara de rector jesuita de los de entonces» (Revuelta, 21.XII.2016; 14.XII.2016). 
Teófanes Egido, gran amigo de Revuelta ${ }^{46}$. Lo recibió en cuanto lo pudimos presentar en el Ayuntamiento de Valladolid en abril de 2019. Sin embargo, el que no conoció ya editado, pero pudo leer, resultaba de gran complejidad. Se trataba del encargo realizado por la editorial Cátedra y que se publicó finalmente como El Nacionalcatolicismo. Discurso y Práctica (octubre de 2019). La valoración que Revuelta hizo del manuscrito, en dos ocasiones diferentes, me permitió realizar importantes cambios y modificaciones. Fue una vez más el analista exigente, pero al mismo tiempo generoso que me pedía concluir con un capítulo pormenorizado acerca de la disolución de esta ideología que ha protagonizado tantas manifestaciones y discursos en la historia política de España ${ }^{47}$.

No había dejado de estar presente en mi correspondencia el Revuelta más polifacético y disciplinar como se manifestó en Historia y espíritu en tierras palentinas. Camino de Santiago y otros afanes (2010). Fue precisamente el primer libro que entró en mi nueva casa cuando nos trasladamos la familia en las primeras semanas de 2011 a un nuevo domicilio. Los contenidos de sus páginas son muy variados, «con mucho sabor a ti, sabor como palentino, con Población (localidad que pude ver de lejos cuando este verano veníamos de Santander y paramos en Frómista, pues no lo conocía)», pudiendo aprender en esos «otros afanes» sobre tantos temas como los pueblos de Castilla, el

46 "Hoy he recibido el libro espléndido La mirada de Teófanes Egido. Cronista de Valladolid [...] El libro es un homenaje más, bien merecido, a nuestro historiador y amigo. He visto que has escrito un estudio preliminar completísimo sobre la vida y obra de Teófanes. Tan completísimo que, en la página 62, mencionas nuestro libro en común y me prodigas alabanzas que no merezco. No te contentas con el nombre, pues aludes a que soy palentino de Población de Campos, nacido, como Teófanes, en 1936. Muchísimas gracias. No sé qué día nació Teófanes, pero yo, al haber nacido el 1 de enero, soy republicano. Me gustaron también, las fotos donde aparece el carmelita, el licenciado y el catedrático» (Revuelta, Salamanca, 11.IV.2019).

47 «Creo que tu libro se convertirá en el libro clásico del nacionalcatolicismo, por la amplitud con la que desarrollas el asunto, arrancando de los precedentes remotos. El capítulo V es el que más me ha gustado [...] a mi juicio es el más interesante porque se concentra en temas concretos: devoción al Sagrado Corazón, a la Virgen, a Santiago y cierra España, a la santa de la raza, al intento de canonización de Isabel la Católica, a los modelos de mujer (con la figura de la palentina Carmen Cuesta que juntaba la apertura con algunos criterios nacionalcatólicos). El capítulo VI [que había sido sugerencia de Revuelta] está bien puesto para analizar el fin del proceso, centrándolo en dos causas fundamentales: la teología del Vaticano II y el contexto de los cambios durante el último franquismo. Todo llevó a un "cuestionamiento" y derribo de nacionalcatolicismo. Se menciona con acierto la colaboración con la transición democrática de una Iglesia sin concordato. Las alusiones a las actitudes de eclesiásticos durante el "procés" (no todos son como Omella) significa que los problemas del nacionalcatolicismo no están cerrados» (Revuelta, 18.IX.2018). 
padre Alonso de Bobadilla o el sindicalismo católico agrario. En mi Universidad estaba rodeado de algunos profesores palentinos que además eran sus compañeros en la Academia Tello Téllez de Meneses —en la que entró el 4 de mayo de 1992-. Así pues, en cada libro que llegaba a casa de este historiador había mucho de esa amistad: "gracias por hacerme disfrutar con la lectura. Desde mi nueva biblioteca, donde tú tienes tantos espacios» (Burrieza, 13.II.2011). Él me confesaba que en este libro había:

[...] algo de biografía, un poquito de ciencia y mucho de corazón. Para mí ha sido el libro más fácil de hacer. Es un cajón de sastre en el que hay de todo: desde escritos de devoción propios de hoja parroquial hasta conferencias con notas eruditas para acabar con la lista de mis publicaciones. Es un libro pueblerino y provinciano en el que domina, como has notado con mucha perspicacia el recuerdo de mis padres, con los que siempre tendré una deuda de gratitud. El caso es que este libro, escrito a la chita callando, está gustando o al menos, sorprendiendo. A este paso acabará clasificado entre los raros y curiosos.

Y aunque se podía llegar a quejar de la oportunidad de las conmemoraciones históricas, gustaba de celebrarlas como sucedió con la madre Teresa de Jesús y las tierras palentinas, un «librito» de más de doscientas páginas que tardó en salir, prologado por su amigo Teófanes Egido ${ }^{48}$. De esta manera, junto a libros, congresos, informaciones, novedades académicas y amistad de la personal, como veremos al final, tampoco estaba ausente en nuestra correspondencia la cotidianidad de la Compañía, en estos años —entre 2003 y 2019- donde han existido tantos hitos interesantes y donde no han faltado las controversias.

Una de las polémicas, en el ámbito eclesial, la protagonizó el padre Juan Masiá, con sus declaraciones sobre moral sexual. Era director de la cátedra de bioética en la Universidad Comillas y profesor invitado de Antropología Filosófica. Hasta 2005 había sido misionero en Japón y profesor de la Universidad de Sofía y cuando este conflicto se produce con la jerarquía española y vaticana era morador de la comunidad donde vivía Revuelta — «hombre inteligente, abierto y valiente, con el peligro de que le manden un aviso»- Y Yo le puse a nuestro historiador en relación, a través de nuestra correspondencia, de las referencias que habían salido en aquellos días en la prensa acerca de sus declaraciones: «los temas de bioética son

48 «Me dices que has recibido el libro Las tres estancias de Santa Teresa en Palencia, al que juzgas con la benevolencia que muestras en todas mis cosas. Al menos el libro salió, aunque con mucho retraso, pues recordarás que lo estaba esperando cuando viniste a Madrid a principios de octubre. Por eso no pude incluir en la bibliografía tus Letras Descalzas, que ese sí que es un libro teresiano» (Revuelta 23.II.2016). 
muy complicados. Hay que mantener los principios, pero hay que estar abiertos a la investigación, evitando los dos extremos lo que no es fácil» (Revuelta, 3.XII.2005). Las presiones sobre estas declaraciones por parte de algunos miembros de la jerarquía eclesial española, bien conectada con la del Vaticano, condujeron a que Masiá fuese apartado de la cátedra universitaria, al secuestro de una de sus obras y a conducirlo a la jubilación con cierta premura. Revuelta subrayaba que su compañero no se había percatado que España no era Japón, donde sus obispos le debían apreciar mucho, y que sus palabras no podían disociarse de su condición de jesuita, lo que suponía una implicación de toda la Compañía. Y en las cartas me ponía otros ejemplos como el del profesor Marciano Vidal que tuvo que presentarse ante la Congregación de la Doctrina de la Fe, presidida años atrás por el cardenal Ratzinger - futuro Benedicto XVI- del que «recibió muy buena impresión por su comprensión y trato humano». Era, pues, el tiempo de la prudencia y no tanto de las actitudes «martiriales» frente a la vigilancia a la que se veían sometidos los profesores de moral (Revuelta, 29.I.2006).

Dos años después, la Congregación General había elegido como prepósito general, en sustitución del padre Kolvenbach, a un español, palentino para más señas, Adolfo Nicolás. Recibía, como colaborador del periódico Diario de Valladolid-El Mundo, los primeros datos de parte de Manuel Revuelta para poder elaborar, aquel sábado 19 de enero de 2008, un artículo sobre el nuevo "Papa negro» ${ }^{49}$. La última responsabilidad del padre Nicolás había sido la de moderador de la Conferencia de Provinciales jesuitas de Asia Oriental y Oceanía. Nacido en 1936, unas pocas semanas después de que lo hiciese Revuelta, el nuevo prepósito general había estudiado el bachillerato en el colegio madrileño de Areneros, pero su entrada en la Compañía también se había producido en 1953. Eso sí, su noviciado discurrió en el noviciado propio de la entonces provincia de Toledo, en Aranjuez.

Y si antes le veíamos en los aniversarios internacionales e históricos de la Compañía o en los centenarios de mujeres tan «teatinas» como santa Teresa, Revuelta también era el hombre adecuado, la palabra autorizada para las celebraciones gozosas de la Compañía. Disponía de la autoridad historiográfica

49 «Ayer el P. Fernando de Lasala, profesor de la Facultad Eclesiástica de la Gregoriana (al que le dirigí la tesis sobre el colegio de Orihuela) me escribía un email felicitándome por el P. General palentino, y me decía, expresamente, que le había gustado mucho el artículo que había escrito Javier Burrieza en El Mundo digital. Yo intentaré ver el artículo, pero no me salía en las claves de El Mundo. Supongo que por no encontrar la edición para Castilla y León. Te lo digo de todos modos, para que veas que tu artículo se difundió fuera de España y mereció el elogio de los expertos. Mucho me alegro y nada me extraña» (Revuelta, 22.I.2008). 
para hacerlo, pues no era un mero cronista. Relataba en mayo de 2011 como había viajado a la celebración de los 450 años del colegio de Montesión de Mallorca, conmemoración impulsada por los antiguos alumnos. La Eucaristía había estado presidida por monseñor Ladaria, antiguo alumno, antiguo residente «ejemplar y humilde» compañero suyo en Cantoblanco, después cardenal y prefecto de la Congregación para la Doctrina de la Fe con el papa Francisco. Entonces, de nuevo, la palabra autorizada para glosar la trayectoria fue Revuelta, que se convirtió en socio de honor de aquella Asociación (Revuelta, 15.V.2011). La culminación de esta cotidianidad jesuítica fue la elección del papa Francisco, el cardenal Jorge Mario Bergoglio, el primer miembro de la Compañía que ha sido elegido romano pontífice:

[...] la verdad es que el papa Francisco ha empezado con buen pie. Rezando y pidiendo oraciones, hablando de Cristo como modelo de la Iglesia, y aspirando a cumplir el mensaje de fraternidad y pobreza de Francisco de Asís. Si se añade el espíritu de Ignacio y el celo de Javier no se puede pedir más. Lo de Clemente XV [se refiere a la sugerencia irónica que le hizo un cardenal de llamarse Clemente para superar a Clemente XIV, el papa que disolvió la Compañía] hubiera sido un gesto de humor negro». (Revuelta, 17.III.2013)

\section{EL JESUITA AFECTUOSO}

«Mirad la bandera / que eleva en España / Javier que a las Indias / a Cristo acompaña / su fe predicando / más limpia que el sol / Javier nos invita: / venid misioneros venid / Juremos por Cristo / luchar los primeros / pues rey se ha llamado / del pueblo español». Querido Javier, mientras arreglaba el cuarto («composición de aposento" que dicen las antiguas prácticas) me dio por tatarear el himno a san Francisco Javier que cantábamos en el colegio de San José en tiempos ya lejanos, más cercanos al colegio de Curía que al colegio actual. Eran tiempos de grandes fervores misionales. Además del Domund, había una asociación, la JEM (Juventud Española Misionera) que tenía su bandera, que sacaban en las misas junto con la bandera de la Congregación. Todo esto sirva de prolegómenos para el objeto de mi carta, que es felicitarte de todo corazón. (Revuelta, 3.XII.2013)

Desde el punto de vista personal, el estudio de la Compañía, como se ha podido comprobar, generó una extraordinaria amistad que, en numerosas ocasiones, fue muy profunda en lo personal y en lo espiritual. Todavía recuerdo aquel curso de verano de finales de septiembre de 2005 en Orihuela, organizado por la Universidad de Alicante, donde estábamos invitados Manuel Revuelta, Isidoro Pinedo, Inmaculada Fernández y un servidor entre otros. Nada más llegar a aquella localidad y después de haber visitado su 
seminario en lo alto de la localidad, al regresar todos junto al hotel, Revuelta en nuestra compañía tuvo conocimiento de la muerte de su madre, a la que había atendido en los últimos meses personalmente cada uno de los días. Rápidamente regresó a Madrid donde ya se encontraba en la medianoche de ese día 27, hasta que partieron a Población de Campos donde recibió sepultura, acompañado nuestro historiador por treinta jesuitas: «es el momento de creer - escribía en la carta del día 30 de septiembre-, de manera existencial, en Dios creador y redentor de nuestra vida. Es el momento de dar inmensas gracias a Dios por el regalo de nuestros padres que tanto nos han amado y nos han precedido en la señal de la fe» (Revuelta, 30.IX.2005). El texto preparado por Revuelta para aquel curso de verano fue leído por el mencionado Isidoro Pinedo. Él no dejaba de felicitarme el día de mi santo, el 3 de diciembre y después, con los años, lo pasamos muchas veces juntos porque coincidía con mi docencia en el Máster Ignaciano de la Universidad Comillas, jornadas en las que me hospedaba en su Residencia.

El historiador no se integra afectuosamente con los temas que explica, pero el padre Revuelta era uno de mis nexos afectivos con la Compañía y con muchos de sus miembros. Recuerdo la desaparición tan sentida como accidental de otro historiador como fue Rafael Sanz de Diego. En la necrológica de $\mathrm{ABC}$ definía que su existencia estaba marcada por tres facetas que se fundían en una única persona: su vocación religiosa, su condición de historiador y la de educador: «era un intelectual que nunca dejó de lado su vocación pastoral. Hablaba muy bien, con frases ingeniosas, tocadas de humor. Era cordial y humano. Fue un profesor universitario ejemplar como catedrático de Historia de la Iglesia de la Facultad de Teología, hombre decidido y emprendedor, con dotes de mando que puso de manifiesto en sus cargos» (Revuelta, ABC, 1.IX.2015).

Revuelta siempre estaba atento y cariñoso a multitud de acontecimientos, por ejemplo, cuando escuchaba una retransmisión de Cope, desde Valladolid y en el Viernes Santo, del Sermón de las Siete Palabras o cuando escuchó el pregón de Semana Santa que tuve el honor de pronunciar en 2013 en la ciudad de los Almirantes, en Medina de Rioseco ${ }^{50}$ : «mucho me alegro de es-

50 «Excelente la idea de ir glosando la pasión a través de los pasos que desfilan junto a los soportales y calles de la vieja y noble ciudad de los Almirantes. Es como hacerse presente a la escena, que decía San Ignacio, con esa magia de revivir la pasión de Cristo, reflejada en las tallas de los imagineros de la edad de oro, y prolongada hasta el día de hoy. La Virgen de Nazaret es la Virgen del pañuelo; y el Jesús del Calvario es el Cristo del Amparo, la Paz o la Clemencia. Los personajes de los Torozos. Los cofrades se ponen en la línea de las generaciones pasadas, unidas en una veneración de la muerte de Cristo que es Resurrección» (Revuelta, 4.IV.2013). 
tas actividades culturales muy valiosas, no sólo por su contenido religioso y humano, sino también por la difusión que tienen en gran número de oyentes o lectores en los medios de comunicación social. Es un campo que nunca debemos abandonar. Es un don que debes seguir explotando» (Revuelta, 13.IV.2007). Como decía en otro momento, los artículos en prensa, "hacen mucho bien y son un buen complemento a las obras de investigación» (Revuelta, 1.VIII.2011). El amigo historiador estaba siempre atento a los acontecimientos personales. Cuando mi hijo Joaquín hizo su primera comunión en mayo de 2018 le escribió una preciosa carta: «El Señor se acerca a ti de una manera especial en un momento de tu vida, lleno de esperanzas [...] con todo cariño de tu amigo jesuita, que reza por ti en este día de Pentecostés» (Revuelta, 20.V.2018). Desde su correspondencia, el amigo jesuita tampoco dejó de estar presente aquel 26 de junio de ese mismo año, en que se celebraba mi oposición de profesor titular en la Universidad de Valladolid.

$$
* * *
$$

Y todas estas cualidades se manifestaron hasta el final. La Universidad Comillas continuaba ofreciendo nuevos libros por él firmados, recopilando trabajos ya publicados u ofreciendo otros inéditos que se quedaron en el inexplicable silencio de un conferenciante. Así sucedía con Enigmas históricos de la Iglesia española contemporánea (2017), donde encontramos, por ejemplo, una completa evolución histórica de la devoción del Sagrado Corazón de Jesús o unas deliciosas páginas sobre el santo jesuita José María Rubio, quizás desde las que escribió en su canonización en 2003. De estas páginas se hizo eco, por ejemplo, la revista Ecclesia. Se unía, con menos repercusión, pero con una importancia cualitativa enorme, un estudio sobre la historiografía jesuítica contemporánea. Contemplaba como muchos vacíos se sucedían en la Compañía. En enero de 2018 moría Isidoro Pinedo en Loyola, «ayer estuvimos en Alcalá al funeral del P. Vargas Machuca [...] Hoy ha fallecido en Alcalá el P. Mendizábal, fundador de unas religiosas y gran propagador de la devoción de la devoción al Sagrado Corazón. Todos nos dejan un ejemplo digno de imitar, aunque el vacío no se puede llenar fácilmente tal como están las vocaciones. El martes estuve en Palencia, con la pena de que en el mes de junio se cerrará aquella residencia» (Revuelta, 19.I.2018), tal y como dejó plasmado también en El Norte de Castilla (10.VI.2018). A pesar de todas las dificultades, conseguí que hiciese su juramento como perito en la Comisión histórica de la causa de la monja dominica Teresa Ortega, del monasterio de la Madre de Dios de Olmedo. Finalmente, estaba convencido de que, con Jesús María Palomares, Emilio Callado, él y yo, habíamos formado una 
buena comisión histórica para aquel proceso de santificación de una monja reformadora y fundadora del siglo XX. El problema es que Revuelta se nos habría de ir demasiado pronto.

Cuando llegó ya enfermo a Salamanca, se encontró en aquella casa con Urbano Valero, jesuita español que lo había sido casi todo en los días del general Pedro Arrupe y que entonces, con noventa años, estaba preparando la edición castellana de la obra de Gianni La Bella sobre la Compañía de Jesús desde el Vaticano II y hasta el papa Francisco. Valero, como lo definió en esta correspondencia años antes, era una "gran persona, rector que fue de Valladolid, provincial de Castilla y de España, asistente y consejero del Padre General». Recensionó varias de nuestras obras en Archivum Historicum Societatis Iesu. Así, aquella mañana de marzo de 2019, cuando Revuelta nos servía de guía por su última casa - la primera también-que tuvo en la Compañía, con sus observaciones vitales e históricas, mi mujer y yo nos pudimos detener con él en la habitación del padre Valero. Un encuentro deseado pues tanto nos habíamos leído y citado. Nos explicó cómo estaba preparando aquella edición y lo poco que le restaba para su conclusión. Le pudimos felicitar por su reciente título sobre Pablo VI y los jesuitas. En realidad, quedamos admirados de su lucidez y vitalidad intelectual ${ }^{51}$.

A Revuelta le dio tiempo, en unas semanas de mejora de salud que tuvo desde su grave operación en enero de 2019, a dedicar su última recensión, el postrero de sus análisis en una revista científica, acerca de la mencionada obra sobre la relación entre el papa Montini y la Compañía, periodo tan vital y que complementaba tanto el otro título de La Bella. Quizás el historiador recordaba cómo Urbano Valero había analizado nuestro libro «tripartido». Revuelta, en la que fue la última carta que me remitió desde Salamanca, el 11 de mayo de 2019, me enviaba esa recensión amplia y detallada, dedicada a la obra mencionada de Urbano Valero:

El papa Pablo VI ha sido recientemente canonizado el 14 de octubre de 2018; y el 5 de febrero de 2019 se inició el proceso de beatificación del Siervo de Dios P. Pedro Arrupe. Este libro viene a ser un homenaje a estos dos hombres santos, que tanto se han distinguido en la renovación de la Iglesia iniciada con el Concilio Vaticano II. Pablo VI mantuvo con la Compañía de Jesús una relación «intensa y complicada» como dice el subtítulo del libro. Una intensidad basada en el amor innegable que el papa profesaba a la Compañía. Y una complicación que se manifiesta en algunos desencuentros entre el Papa Montini y el General Arrupe. Estudiar sus encuentros y desencuentros, como se hace en este libro, ilumina en gran medida la forma en que uno y otro gobernaron la Iglesia y la Compañía. El autor [Urbano Valero] es una persona muy bien preparada para tratar del tema

51 Valero, 2019; La Bella, 2019. 
bajo el punto de vista histórico, jurídico y personal. Aunque el Archivo Secreto Vaticano sigue cerrado a los investigadores sobre el último cuarto del siglo XX, el autor considera que existe suficiente información para el desarrollo del tema, que cuenta ya con abundante bibliografía [...] Es, además, un gran conocedor del Instituto bajo el punto de vista histórico-jurídico, como lo ha demostrado en su contribución decisiva en la elaboración de las «normas complementarias» de las Constituciones, normas aprobadas en la Congregación General 34 (1995).

El padre Valero moría pocos días después de esta carta última de Revuelta, víctima de una rápida infección producida por una intervención quirúrgica. La misiva comenzaba con el agradecimiento por haberle enviado el prólogo de la última obra de Manuel de los Reyes sobre el jesuita Marcelino de la Paz: «supongo que en el libro no dejará de decir que provenía de la diócesis de Palencia». El deterioro de su salud no le permitía decir mucho más. Justo un mes antes se había despedido en otra de la manera habitual, como venía sucediendo desde la primera de 2003: «saludos a María José, y besos a los chicos. Un abrazo muy cordial de este buen amigo. Manolo Revuelta SJ» ${ }^{52}$.

\section{REFERENCIAS}

Astorgano, A. (2020). Manuel Revuelta, un historiador de la Compañía de Jesús Ejemplar. In Memoriam. Montalbán, nº 55, enero-junio 2020, pp. 32-95.

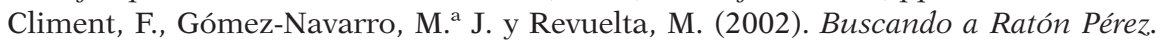
Estudio del Cuento Infantil del P. Luis de Coloma SJ. Madrid: Asociación Española de Amigos del Libro Infantil y Juvenil.

Eguillor, J.R., Revuelta, M. y Sanz de Diego, R. M. ${ }^{a}$ (eds.) (1988). Memorias del P. Luis Martín, General de la Compañía de Jesús (1846-1906). 2 tomos, Madrid.

Fernández Arrillada, I. y Martínez Tornero, C. (eds.) (2015). Estudio introductorio de Manuel Revuelta. Diario de 1814 y 1815. El final del destierro y la restauración de

52 Carta de Manuel Revuelta a Javier Burrieza, Salamanca 11 abril 2019. Esta y la mencionada de 11 de mayo, fueron las únicas escritas desde la Enfermería de Salamanca. Allí, el contacto permanente fue telefónico. Hablé con él cinco días antes de su muerte: simplemente me dijo que estaba «muy mal». El superior me indicó que algunos días eran mejores y otros peores, pero que la situación no había cambiado. El mismo día de su fallecimiento, 16 de julio, saliendo de la Facultad, a las diez y media de la mañana, tuve el particular impulso de llamar a Salamanca. Por primera vez me quisieron pasar con el enfermero. No me respondió. Me dijeron que lo intentase diez minutos más tarde. Al terminar el trayecto volví a llamar y me comunicaron su muerte. Fue Antonio Pérez García el que realizó la necrológica de Manuel Revuelta González (1936-2019), publicada en la página de la Provincia de España de la Compañía de Jesús. Utilizó el mencionado texto inédito de las Memorias de Manuel Revuelta. 
la Compañía de Jesús. Manuel Luengo SI. Alicante: Universidad y Madrid: Universidad Pontificia Comillas.

Ferrer Benimelli, J.A. (2013). Expulsión y extinción de los jesuitas 1759-1773. Bilbao: Ediciones Mensajero.

Giménez López, E. (ed.) (2010). Aspectos de la política religiosa en el siglo XVIII. Estudios en Homenaje a Isidoro Pinedo Iparraguirre SJ. Alicante: Universidad.

La Bella, G. (2019). Los jesuitas. Del Vaticano II al papa Francisco. Presentación de la edición española por el padre Urbano Valero, Bilbao: Mensajero.

Labrador, C. (2019). El sistema educativo de la Compañía de Jesús: Ratio Studiorum. En Burrieza Sánchez, J. (Coord.). Los trabajos y los días de San Juan Bautista De La Salle. Madrid: Dykinson. 83-112.

López Calo, J. (2010). Nemesio Otaño, SJ. Medio siglo de música religiosa en España. ICCMU, Colección Música Hispana. Textos, Biografías, Madrid.

Martínez Millán, J., Pizarro, H., Jiménez, E. (coords.) (2012). Los jesuitas. Religión, política y educación (siglos XVI-XVIII). Madrid: Universidad Pontificia Comillas, 3 tomos.

Revuelta, M. (1999). El Padre Francisco Butiñá en el contexto histórico de la Compañía de Jesús. Miscelánea Comillas, 57, 197-243.

Revuelta, M. (2005). La Iglesia Española en el siglo XIX. Desafíos y respuestas, Madrid: Universidad Pontificia Comillas.

Revuelta, M. (2010). La Exclaustración, Madrid, Fundación Universitaria San Pablo CEU.

Revuelta, M. (2013). El restablecimiento de la Compañía de Jesús. Celebración del bicentenario. Bilbao: Ediciones Mensajero, Grupo Editorial Loyola.

Revuelta, M. (2017). Historiografía de la Compañía de Jesús restaurada en España (1815-2017). Estudios Eclesiásticos, n $361,313$.

Revuelta, M. (2018). Semblanza del P. Quintín Aldea SJ (1920-2012). Anuario

Sanz de Diego, R. (2005). Jesuitas de nuevo. Razón y Fe, no 1275, 85-87.

Usabel, G. de (2010). Biografía incompleta de un historiador del XVIII: Isidoro Pinedo Iparraguirre. En Giménez López, E. (coord.). Aspectos de la política religiosa en el siglo XVIII. Estudios en homenaje a Isidoro Pinedo Iparraguirre. Alicante: Universidad.

Palacios Bañuelos, L. (ed.) (2013). Vicente Palacio Atard, maestro de historiadores. León: Akrón.

Valero, U. (2019). Pablo VI y los jesuitas, Bilbao, Mensajero. 


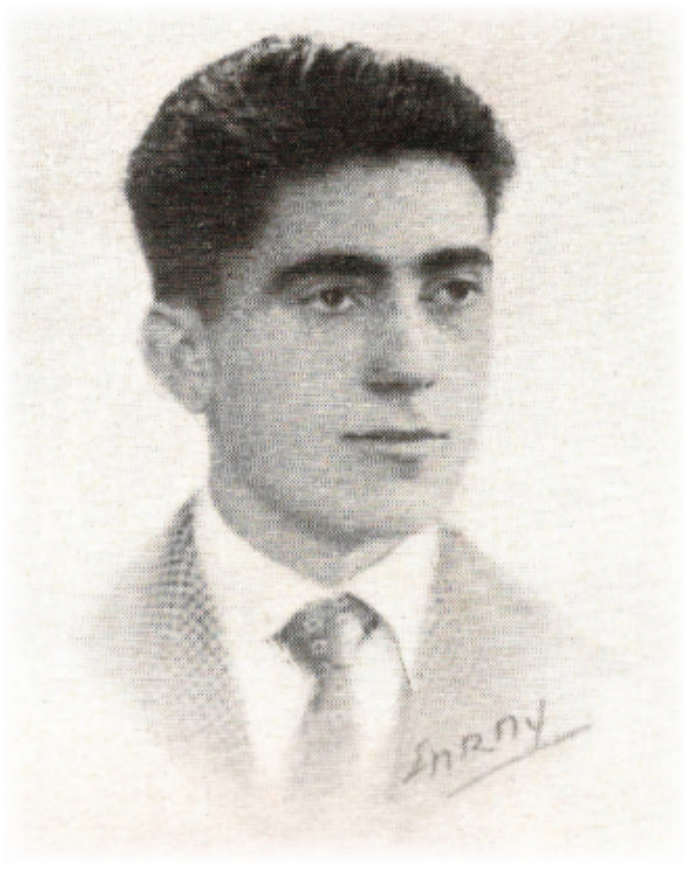

Manuel Revuelta, 1954. (18 años). Alumno del Colegio San José de Valladolid. Foto: Vallisoletana 106 (1954) pág. 8A. Archivo del Colegio San José (Valladolid).

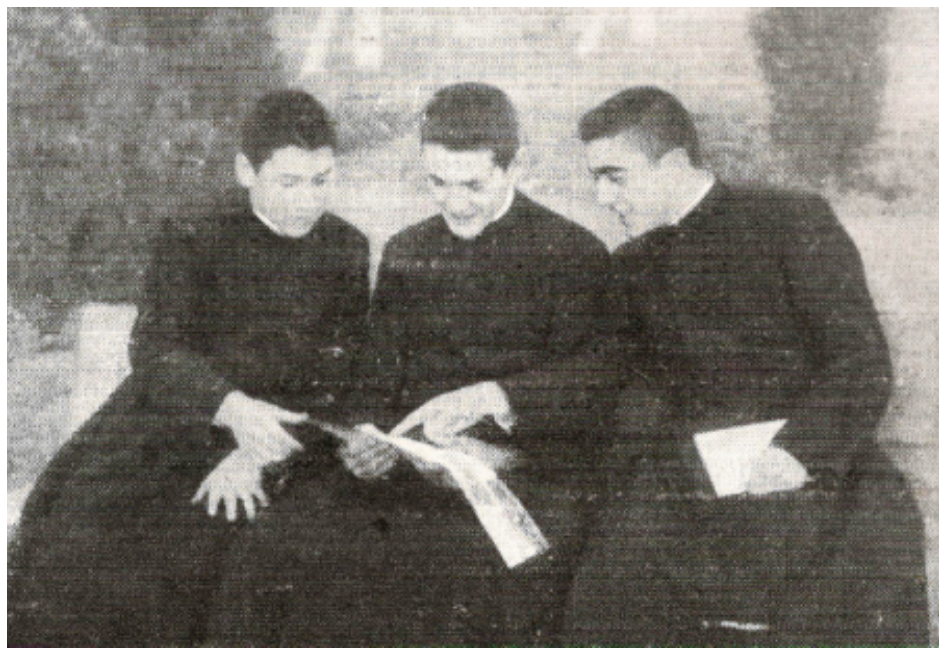

Manuel Revuelta, 1954 (18 años) primero por la derecha. Noviciado en Salamanca junto a Gregorio (Goyo) Ruiz (centro) y Eutiquio Antolín (Tiquines) (izquierda). Foto: Vallisoletana 106 (1954), pág. 7B. Archivo del Colegio San José (Valladolid). 


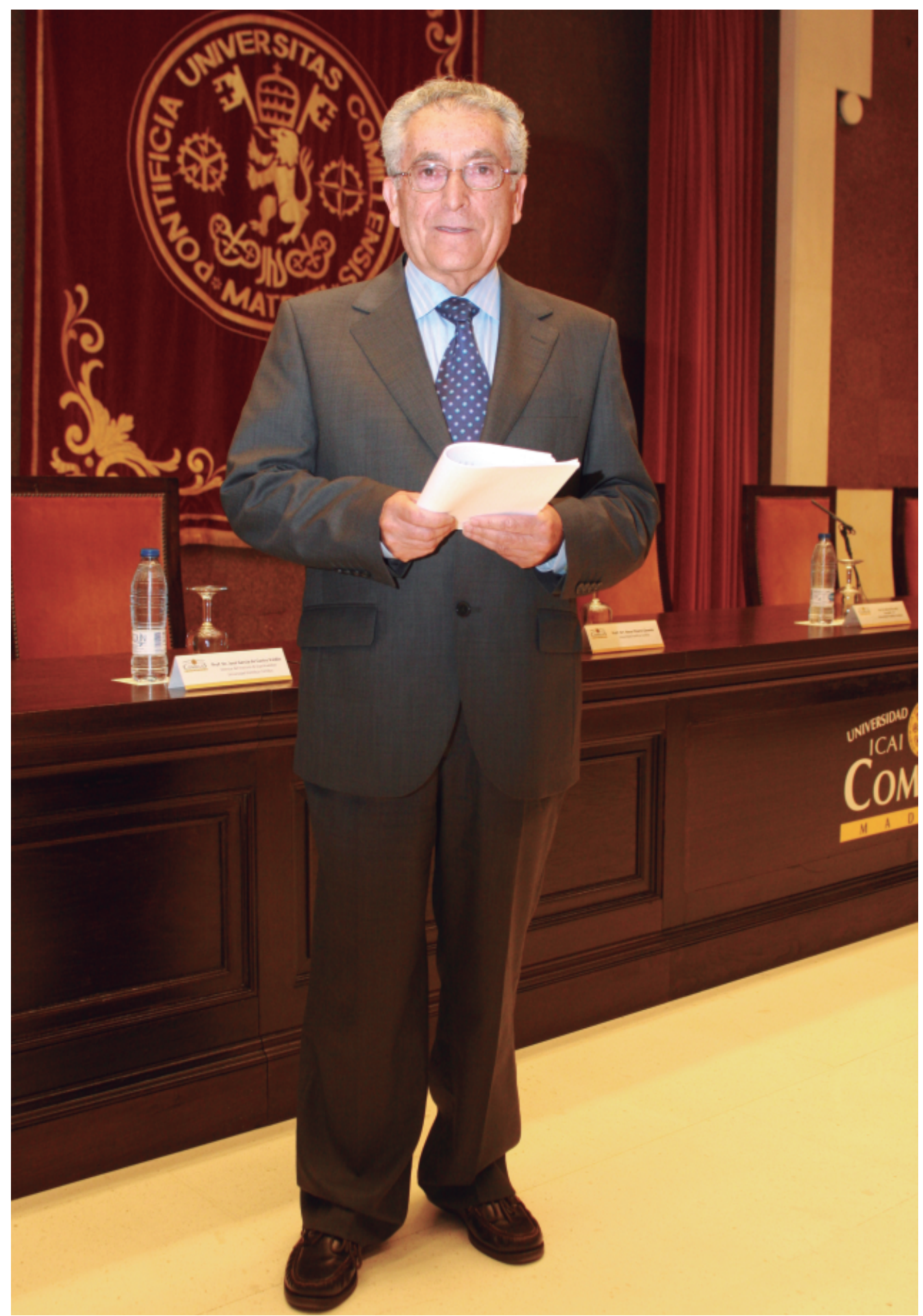

Manuel Revuelta, 22 de junio de 2011. Aula Magna de la Universidad Pontificia Comillas (Madrid). Congreso Internacional: «Jesuitas: Religión, Política y Educación». Foto: Archivo de la U.P. Comillas (Madrid). 


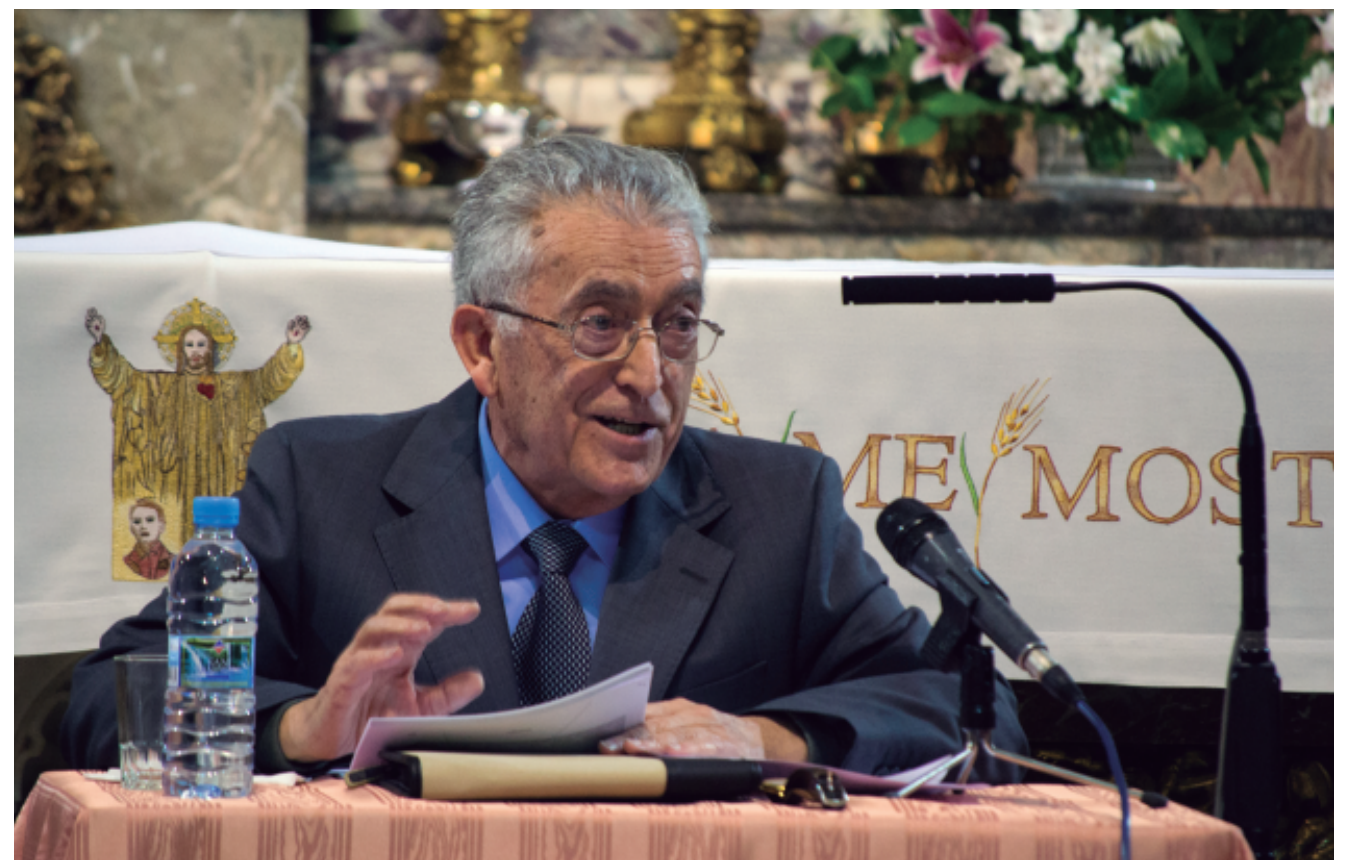

Manuel Revuelta, 28 de noviembre de 2012. Santuario Nacional de la Gran Promesa (Valladolid). Conferencia: «Evolución histórica de la Devoción al Sagrado Corazón de Jesús». Foto: Angel Cantero (Valladolid).

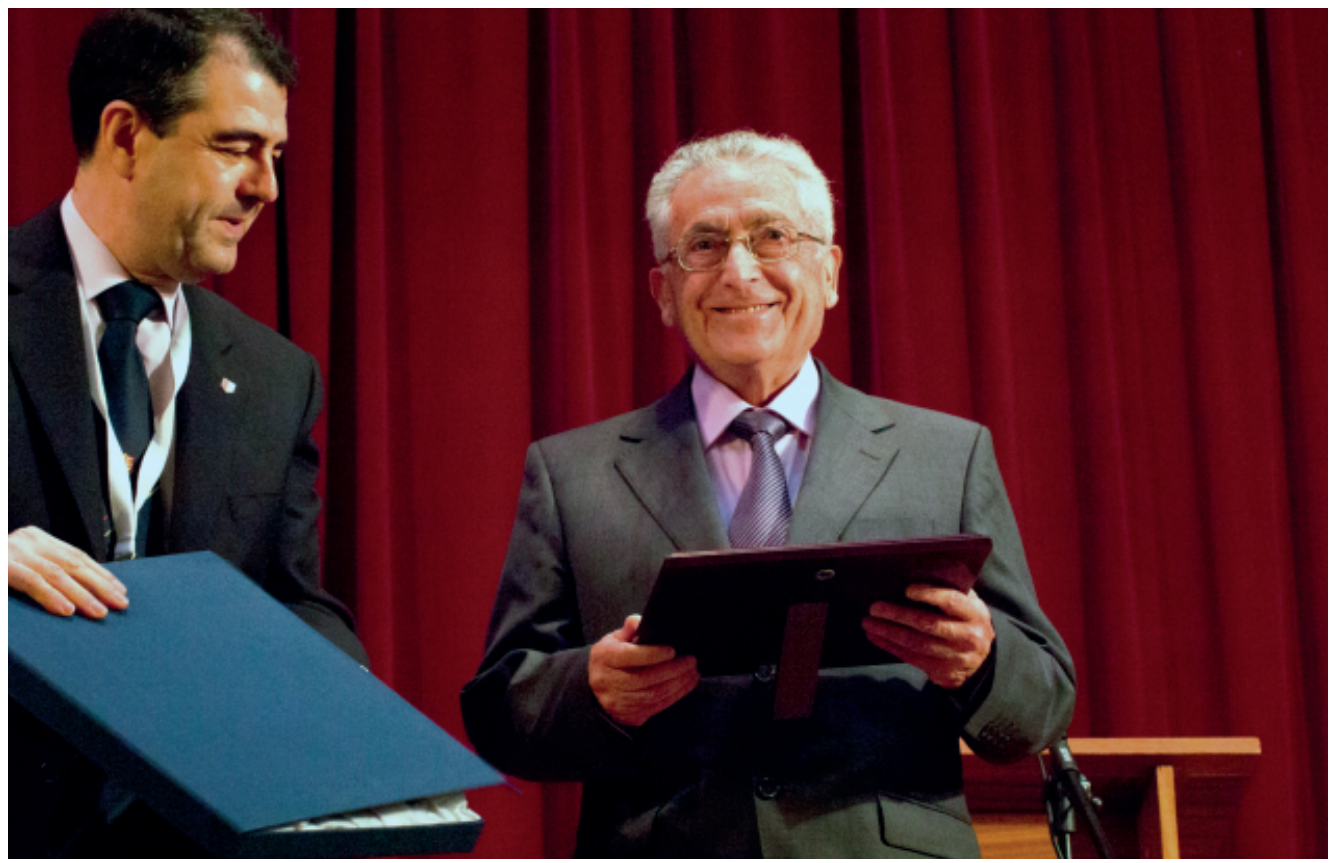

Manuel Revuelta, 8 de junio de 2014. Recibiendo la distinción de «Alumno Distinguido del Colegio San José de Valladolid» de D. José Pablo Hernández, presidente de la Asociación de Antiguos Alumnos. Foto: Archivo del Colegio San José (Valladolid). 


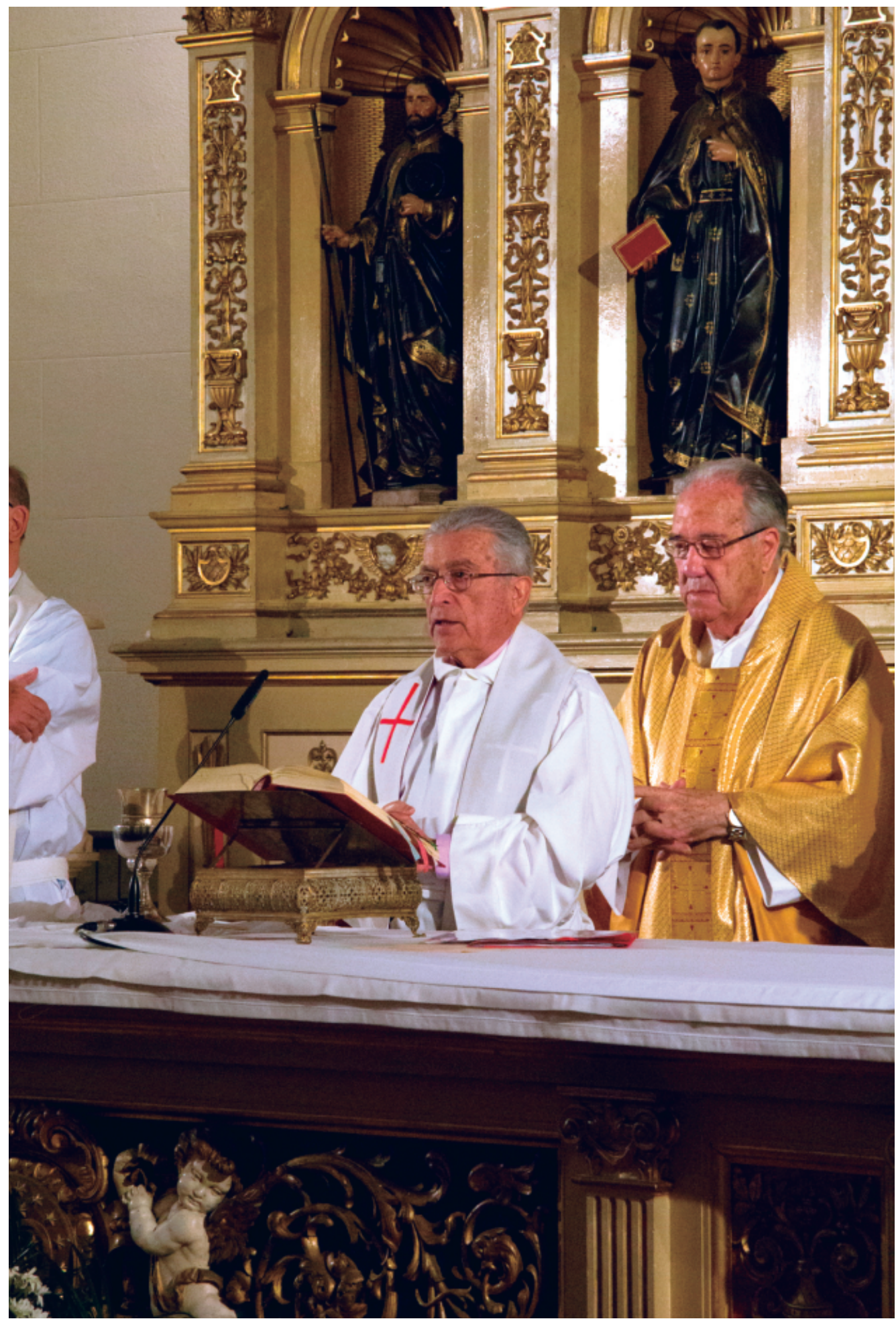

Manuel Revuelta, 8 de junio de 2014. Celebración de la Eucaristía en la capilla del Colegio San José el día de la distinción de «Alumno Distinguido del Colegio San José de Valladolid». Foto: Archivo del Colegio San José (Valladolid). 